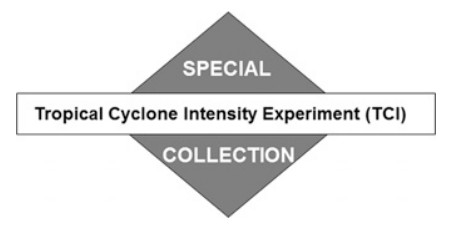

\title{
Examination of the Expendable Digital Dropsonde-Derived Vertical Velocities from the Tropical Cyclone Intensity (TCI) Experiment $\mathscr{D}$
}

\author{
T. CONNOR NELSON AND LEE HARRISON \\ Atmospheric Sciences Research Center, University at Albany, State University of New York, Albany, New York \\ KRISTEN L. CORBOSIERO \\ Department of Atmospheric and Environmental Sciences, University at Albany, State University of New York, Albany, New York
}

(Manuscript received 28 November 2018, in final form 22 April 2019)

\begin{abstract}
The newly developed expendable digital dropsonde (XDD) allows for high spatial and temporal resolution data collection in tropical cyclones (TCs). In 2015, a total of 725 XDDs were launched into Hurricanes Marty (27-28 September), Joaquin (2-5 October), and Patricia (20-23 October) as part of the Tropical Cyclone Intensity (TCI) experiment. These dropsondes were launched from a NASA WB-57 at altitudes above $18 \mathrm{~km}$, capturing the full depth of the TCs to the tropopause. This study documents the vertical velocity distributions observed in TCI using the XDDs and examines the distributions altitudinally, radially, and azimuthally. The strongest mean or median XDD-derived vertical velocities observed during TCI occurred in the upper levels and within the cores of the three TCs. There was little azimuthal signal in the vertical velocity distribution, likely due to sampling asymmetries and noise in the data. Downdrafts were strongest in Joaquin, while updrafts were strongest in Patricia, especially within the eyewall on 23 October. Patricia also had an impressive low-level $(<2 \mathrm{~km})$ updraft that exceeded $10 \mathrm{~m} \mathrm{~s}^{-1}$ associated with a shallow, overturning, radial circulation in the secondary eyewall.
\end{abstract}

\section{Introduction}

The introduction of the high-definition sounding system (HDSS) and its expendable digital dropsondes (XDDs) has increased the spatial resolution of global positioning system (GPS) dropwindsondes (hereafter, referred to as "dropsondes" or "sondes") in tropical cyclones (TCs; Black et al. 2017). The HDSS can launch sondes as frequently as once every $10 \mathrm{~s}$ and the telemetry capacity allows for the data acquisition of as many as 40 sondes simultaneously. The HDSS/XDD system used during the 2015 Office of Naval Research (ONR) funded Tropical Cyclone Intensity (TCI) experiment could carry up to 96 sondes and most flights released more than 57 sondes (Doyle et al. 2017). With the high spatial and temporal resolution of sondes from the HDSS, the

\footnotetext{
Supplemental information related to this paper is available at the Journals Online website: https://doi.org/10.1175/MWR-D-180414.s1.
}

Corresponding author: T. Connor Nelson, ccnelson@albany.edu radial, azimuthal, and altitudinal frequencies of vertical velocities can be analyzed for the individual TCs observed during TCI. The purpose of this study is to document the strength and location of sonde-derived vertical velocities in the TCI dataset, as well as to examine the updrafts and downdrafts observed by the XDDs.

Hock and Franklin (1999) used RD-93 dropsondes to derive vertical velocity from GPS fall speeds and a single drag force estimate presumed to be representative for all individual sondes. This method is now routine, but more recent studies use a hydrostatic pressure-derived fall speed rather than the GPS fall speed (e.g., Wang et al. 2015). Sonde-derived vertical velocities have been used to examine the specifics of convection, such as misovorticies and extremely strong updrafts below $3 \mathrm{~km}$ (e.g., Aberson et al. 2006; Stern and Aberson 2006; Stern et al. 2016). Most of the data obtained by these sondes, however, yielded lowmagnitude vertical velocities.

Many studies concluded that deep, strong convection and updrafts are important in the intensification of TCs (e.g., Steranka et al. 1986; Vigh and Schubert 2009; Rogers et al. 2016), but others argue that it is not 
(Jiang 2012; Jiang and Ramirez 2013). The discrepancies between these studies demonstrate the need for highquality vertical velocity measurements and further study of TC convection, updrafts, and downdrafts. The examination of updrafts and downdrafts themselves, and their potential impacts on intensity change, in TCs is important. For example, deep-layer shear, and the subsequent asymmetric convection, can lead to short-term TC intensification with weakening thereafter (Kaplan and DeMaria 2003; DeMaria et al. 2012). If there is sufficient energy provided to the TC from the ocean, the cyclone can resist the weakening effects of shear and maintain its strength or intensify (e.g., Black et al. 2002). As strong updrafts are often located near the radius of maximum wind (RMW; Black et al. 1994; Rogers et al. 2013; Stern et al. 2016) or just inside the RMW (Jorgensen et al. 1985; Marks et al. 2008), they can also be associated with intensification following RMW contraction (Stern et al. 2015).

Another unresolved TC intensification processes is the role of small-scale vorticity and collocated updrafts in the vicinity of the eyewall. As described by Persing and Montgomery (2003), TCs can reach intensities higher than their maximum potential intensity (MPI) by mixing high-entropy air from the eye into the eyewall through vorticity maxima at the eye-eyewall interface. This process has been dubbed "superintensity" and has been supported observationally by the analysis of Montgomery et al. (2006). Bryan and Rotunno (2009), however, have shown that this process is inconsequential for a TC to reach its MPI. Regardless, intensity changes below the MPI of a TC due to eye-eyewall mixing ("subMPI intensity changes"; Eastin et al. 2005b) remain plausible and are supported by the findings of Dolling and Barnes (2012).

Updrafts in excess of $10 \mathrm{~m} \mathrm{~s}^{-1}$ have been observed occasionally in TCs below a height of $6 \mathrm{~km}$ (Jorgensen et al. 1985; Aberson et al. 2006; Stern and Aberson 2006; Stern et al. 2016). Stern et al. (2016) and Stern and Aberson (2006) found that extreme updrafts $\left(\geq 10 \mathrm{~m} \mathrm{~s}^{-1}\right)$ observed below $3 \mathrm{~km}$ were often collocated with lowlevel, extreme horizontal wind maxima $\left(\geq 90 \mathrm{~m} \mathrm{~s}^{-1}\right)$ in major hurricanes. Other low-altitude $(<6 \mathrm{~km})$ studies found that updraft strength increases with altitude (Jorgensen et al. 1985) and is strongest within the eyewall (Stern and Aberson 2006; Aberson et al. 2006). In many cases, the updrafts are a part of the asymmetric component of eyewall convection on top of the symmetric component (Eastin et al. 2005a,b). Jorgensen et al. (1985) found that, between 1 and $6 \mathrm{~km}$, the top $10 \%$ of eyewall updraft cores are larger and stronger than rainband updrafts. Stern et al. (2016) and Stern and Aberson (2006) also found that updrafts maximized in strength in the downshear-left quadrant in the core for soundings below $3 \mathrm{~km}$.

Other high-altitude studies $(0-16 \mathrm{~km})$ using flightlevel and Doppler radar data have also occasionally documented updrafts in excess of $10 \mathrm{~m} \mathrm{~s}^{-1}$ in TCs (Black et al. 1994, 1996, 2002; Marks et al. 2008; Heymsfield et al. 2010). These extremely strong vertical motions occur primarily in the upper levels, above $10 \mathrm{~km}$ (Black et al. 1996; Guimond et al. 2010), which is not surprising as vertical velocity tends to maximize aloft between 10 and $15 \mathrm{~km}$ (Black et al. 2002; Heymsfield et al. 2010; Reasor et al. 2013; DeHart et al. 2014). Black et al. (1994) found strong updrafts widely scattered in the mid- and lower levels $(2-6 \mathrm{~km})$ of Hurricane Emily (1987), with small pockets of strong updrafts aloft ( $>6 \mathrm{~km}$ ). Black et al. (1996) observed a relative minimum at $5-6 \mathrm{~km}$ in mean vertical velocity profiles. DeHart et al. (2014) found that strong updrafts in the core tended to occur aloft and primarily in the downshearleft quadrant. Downdrafts tended to occur aloft and in the midlevels in the upshear-left quadrant.

The most accepted, and supported, theory for updraft azimuthal and altitudinal distributions is that updrafts tend to initiate at low levels in the downshear-right quadrant and rise helically to their maximum intensity aloft in the downshear-left quadrant, with downdrafts dominating the upshear quadrants, specifically the upshear-left quadrant (Franklin et al. 1993; Black et al. 2002; DeHart et al. 2014). Black et al. (2002), Zipser (2003), Guimond et al. (2010), Reasor et al. (2013), and DeHart et al. (2014) all show that updrafts maximize in strength in the downshear quadrants of the TC, especially the downshear-left quadrant in the core.

To date, radar, dropsonde, and flight-level data have found very few strong updrafts or downdrafts outside of $100 \mathrm{~km}$ from the storm center (e.g., Black et al. 1996), despite large amounts of lightning occurring in this region (Corbosiero and Molinari 2002, 2003). This apparent discrepancy may be a result of limited samples at large radii, research and reconnaissance flights avoiding strong convection for safety, or relatively large radar volumes that cannot detect small-scale convective features. While the eyewall embodies the primary ascending branch of the secondary circulation (Shapiro and Willoughby 1982), convection outside of the eyewall can be excited by vortex Rossby waves (Black et al. 2002; Corbosiero et al. 2006) or consist of convective clouds stretched and deformed into intense banded structures (Moon and Nolan 2015).

The most recent work on dropsonde-observed updrafts in TCs, Stern et al. (2016), had information for the radial, azimuthal, and altitudinal variances of updrafts in the lowest $2-3 \mathrm{~km}$ and examined updrafts that exceeded 
$10 \mathrm{~m} \mathrm{~s}^{-1}$. In this study, azimuthal, radial, and altitudinal sonde-derived vertical velocity distributions below $17.5 \mathrm{~km}$ from TCI flights into Hurricanes Marty, Joaquin, and Patricia using the HDSS and XDDs (Doyle et al. 2017) are presented through the use of median vertical velocity profiles and contoured frequency diagrams. Bootstrap median significance tests are provided in the online supplemental material to examine statistical differences in the medians of positive and negative vertical velocities within specific sections of the TCs and support the results of this work. Basic characteristics of observed updrafts and downdrafts are also examined. In section 2, the data and methods are described. Section 3 provides an analysis of the data. The last portion, section 4, discusses the results in more detail and proposes future work.

\section{Data and methods}

\section{a. Calculation of vertical velocity}

During the 2015 ONR TCI campaign, 140, 328, and 257 XDD sondes were deployed into Marty (27-28 September), Joaquin (2-5 October), and Patricia (20-23 October), respectively (a total of 725). The sondes were dropped from the National Aeronautics and Space Administration WB-57 aircraft using the HDSS on 1-2-h flights. TCI sampled Marty as a tropical storm (sustained winds of $\left.26 \mathrm{~m} \mathrm{~s}^{-1}\right)$ and a category 1 hurricane $\left(36 \mathrm{~m} \mathrm{~s}^{-1}\right)$ (Berg 2016a). Joaquin was observed as a category $3\left(57 \mathrm{~m} \mathrm{~s}^{-1}\right)$, category $4\left(67 \mathrm{~m} \mathrm{~s}^{-1}\right)$, category $2\left(47 \mathrm{~m} \mathrm{~s}^{-1}\right)$, and category $1\left(39 \mathrm{~m} \mathrm{~s}^{-1}\right)$ hurricane on each day, respectively (Berg 2016b). Patricia was a stronger TC and was observed as a tropical depression $\left(15 \mathrm{~m} \mathrm{~s}^{-1}\right)$, tropical storm $\left(26 \mathrm{~m} \mathrm{~s}^{-1}\right)$, category 4 hurricane $\left(59 \mathrm{~m} \mathrm{~s}^{-1}\right)$, and during rapid weakening from a category 5 hurricane $\left(92 \mathrm{~m} \mathrm{~s}^{-1}\right)$ (Kimberlain et al. 2016).

Hock and Franklin (1999) derived vertical velocity from dropsondes by assuming all RD-93 sondes had an identical open parachute area and drag coefficient determined from wind tunnel testing, yielding:

$$
\begin{aligned}
F_{d} & =\frac{1}{2} C_{d} A \rho V_{s}^{2}, \\
w & =V-V_{f},
\end{aligned}
$$

where $F_{d}$ is the drag force, $C_{d}$ is the drag coefficient, $A$ is the drag-affected area, $\rho$ is the atmospheric density, and $V$ is the still-air velocity. Vertical velocity $(w)$ is the difference between the still-air fall speed and the recorded fall speed $\left(V_{f}\right)$. If the drag force is assumed to be equal to the product of mass and gravity, then Eq. (1) can be rewritten as

$$
V=S \sqrt{\frac{2 g}{\rho},}
$$

where $S$ is called the sonde parameter:

$$
S=\sqrt{\frac{m}{C_{d} A}} .
$$

With the XDD sondes, no parachute is used, and the drag depends on the drag of the sonde body alone. While the mean fast-fall, sea level descent rate was found to be approximately $18 \mathrm{~m} \mathrm{~s}^{-1}$ by Black et al. (2017), and a mass and sonde diameter were presented, neither the drag coefficient for the XDDs, nor the variability in the mass or drag coefficient, is currently known. The sonde parameter can be calculated directly by evaluating Eq. (3) if the still-air fall speed and density are known. Therefore, to calculate vertical velocity, the following approach was used:

$$
\begin{gathered}
V_{o}=S_{p} \sqrt{\frac{2 g}{\rho_{o}}}, \\
V=V_{o} \sqrt{\frac{\rho_{o}}{\rho}},
\end{gathered}
$$

where a median sonde parameter $\left(S_{p}\right)$ is calculated using Eq. (3), the last data point density, and the last data point GPS fall speed from sondes launched outside of convective regions (see below). The last data point is defined here to be the last recorded data point in the sounding below $500 \mathrm{~m}$. Vertical velocity at these last data points for the sondes launched outside of convective regions is assumed to be negligible (see appendix for error analysis); $V_{o}$ is the estimated sea level still-air fall speed of each individual sonde based upon the median sonde parameter and the last observed data point density below $500 \mathrm{~m}\left(\rho_{o}\right)$ after data quality control and removal have been completed (see below), and $V$ is the theoretical still-air fall speed of a sonde given the density $(\rho)$ profile. Density is defined as the moist ideal gas density using virtual temperature. In situations where moisture data were unavailable, temperature was used instead of virtual temperature.

The still-air fall speeds from Eq. (6) can be used with Eq. (2) and a hydrostatic, or differential pressure ( $\partial p / \partial t)$, indicated fall speed $\left(V_{f}\right)$, similar to recent studies (e.g., Wang et al. 2015; Stern et al. 2016):

$$
V_{f}=\frac{1}{\rho g} \frac{\partial p}{\partial t}
$$




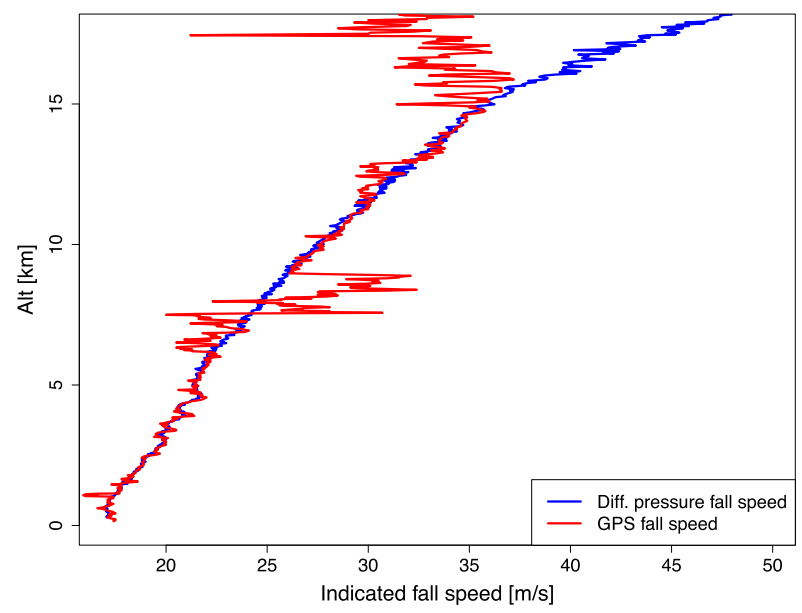

FIG. 1. Erratic GPS fall speed behavior from sounding 1-D-5F4E in Marty on 27 Sep. Plotted in blue is the differential fall speed and in red is the GPS fall speed.

to obtain the vertical velocity. Vertical velocity was computed at a coarser, $1-\mathrm{Hz}$, resolution than the native 4-Hz GPS data acquisition frequency. The differential pressure was computed with a 15 -point centered difference, after removing missing data, rather than from the Atmospheric Sounding Processing Environment (ASPEN) software (Bell et al. 2016), corresponding to a vertical depth of $750 \mathrm{~m}$ at $17.5 \mathrm{~km}$ and $270 \mathrm{~m}$ near sea level, assuming there are no missing data points. The differential pressure fall speed was used in lieu of the GPS fall speed in Eq. (2) due to large, unrealistic discrepancies between the two fall speeds in the midlevels and aloft (e.g., Fig. 1), and because the accuracy of the pressure is better than GPS-height-derived fall speeds (Stern et al. 2016). It should be noted that $V_{f}, V$, and $V_{o}$ are positive going downward, which implies that $w$ is negative for downdrafts. An error analysis for this methodology is provided in the appendix. The typical errors associated with this methodology for the XDDs are approximately $\pm 1-2 \mathrm{~m} \mathrm{~s}^{-1}$. Other methods for obtaining $V_{o}$ and $\rho_{o}$ are analyzed as supplemental material.

Sondes were determined to be launched outside of convective regions if their sounding profiles were unsaturated for the entirety of the descent and if the sonde was launched into an area of infrared (IR) brightness temperatures warmer than approximately $-30^{\circ} \mathrm{C}$, which consisted of 90 dropsondes. An example of IR brightness temperatures on 23 October in Patricia, with sondes launched outside of convective regions indicated by red circles, is provided in Fig. 2. The $-30^{\circ} \mathrm{C}$ threshold matches the warmest IR brightness temperatures for all deep convection following Jiang and Tao (2014). The soundings outside of convective regions were excluded from the vertical velocity analysis.

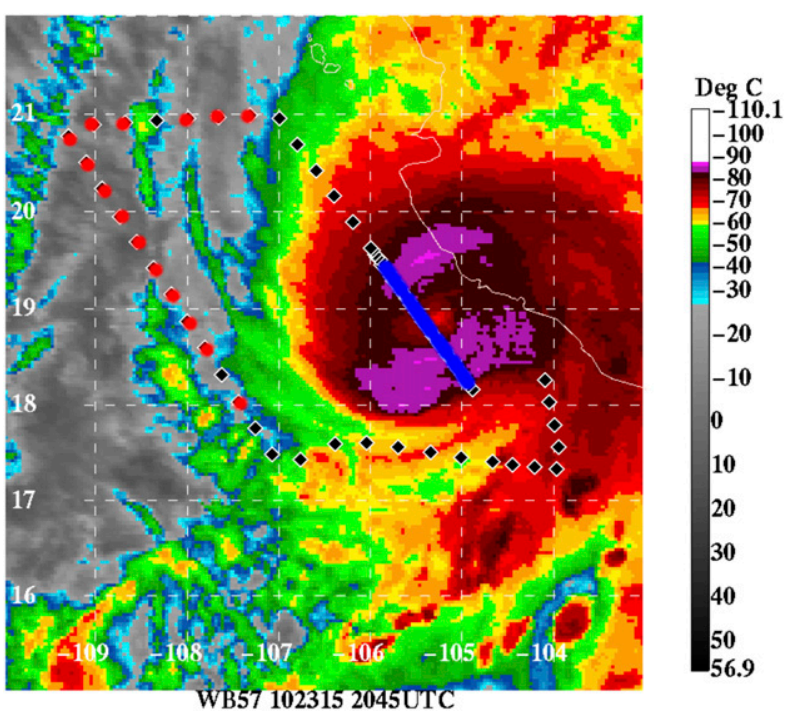

FIG. 2. IR satellite image of Patricia at 2045 UTC 23 Oct 2015. Brightness temperatures $\left({ }^{\circ} \mathrm{C}\right)$ are shaded. Launch locations for soundings outside of convective regions (red), soundings removed from the dataset by quality control or radial restriction (black diamonds), and soundings analyzed in this study (blue) are also included. IR image courtesy of David Vollaro.

The median sonde parameter derived from the last data point data from sondes launched outside of convective regions was $4.22 \mathrm{~kg}^{1 / 2} \mathrm{~m}^{3 / 2}$. The last data point fall speeds fluctuated primarily between 17 and $18.5 \mathrm{~m} \mathrm{~s}^{-1}$, with none less than $14 \mathrm{~m} \mathrm{~s}^{-1}$, and had a standard deviation of $0.89 \mathrm{~m} \mathrm{~s}^{-1}$. The last data point fall speeds outside of one standard deviation from the mean do not appear to be caused by altitudinal variations, which suggests that the altitude of the last data point does not significantly impact the calculation of the median sonde parameter. Most of the last data points in the soundings occurred below $200 \mathrm{~m}$ and in some cases below $100 \mathrm{~m}$. The standard deviation of the last data point densities was also small at $0.01 \mathrm{~kg} \mathrm{~m}^{-3}$.

Sondes were removed from the dataset if their last observed data point was at a GPS altitude greater than $500 \mathrm{~m}$. The rationale for such a restriction was to ensure that the sondes recorded data in the low levels of TCs, comparable to Stern et al. (2016). The data were also restricted to only include data points below an altitude of $17.5 \mathrm{~km}$. While the WB-57 was flown at an altitude of approximately $19 \mathrm{~km}$, most sondes outside of convective regions take approximately $25 \mathrm{~s}$ to reach a stable fall speed after launch, a distance of $0.5-1 \mathrm{~km}$. The altitude restriction of $17.5 \mathrm{~km}$ was chosen to prevent erroneous data and provide an approximate $500-\mathrm{m}$ buffer. Data were also restricted to within an RMW-normalized radius, $R^{*}$, of 10 to eliminate data points that were well removed from the TC. The distances that correspond to $10 R^{*}$ for each day are provided in Table 1. 
TABLE 1. Number of sondes from each day in the dataset $\left(N_{t}\right) . S$ is the deep-layer shear $(850-200 \mathrm{hPa})$ in $\mathrm{m} \mathrm{s}^{-1}$ and $S_{D}$ is the shear direction in degrees clockwise from the north $\left(^{\circ}\right)$. Intensity is the maximum tangential wind speed in $\mathrm{m} \mathrm{s}^{-1}$ at 1800 UTC from the best track database. The $10 R^{*}$ distancs in $\mathrm{km}$ for each day is also provided.

\begin{tabular}{llccrrc}
\hline Day & Name & $N_{t}$ & Intensity & \multicolumn{1}{c}{$S$} & $S_{D}$ & $10 R^{*}$ \\
\hline 27 Sep & Marty & 50 & 26 & 11.21 & 98 & 370 \\
28 Sep & Marty & 58 & 36 & 11.00 & 89 & 210 \\
2 Oct & Joaquin & 44 & 57 & 4.90 & 151 & 310 \\
3 Oct & Joaquin & 43 & 67 & 13.20 & 127 & 270 \\
4 Oct & Joaquin & 55 & 44 & 4.90 & 66 & 380 \\
5 Oct & Joaquin & 53 & 39 & 3.90 & 39 & 490 \\
20 Oct & Patricia & 12 & 15 & 5.25 & 42 & 770 \\
21 Oct & Patricia & 51 & 26 & 2.93 & 195 & 400 \\
22 Oct & Patricia & 43 & 59 & 0.62 & 146 & 190 \\
23 Oct & Patricia & 28 & 93 & 4.58 & 21 & 110 \\
& & & & & & \\
Total & - & 437 & $46(\mathrm{avg})$ & $6.25(\mathrm{avg})$ & - & $350(\mathrm{avg})$ \\
\hline
\end{tabular}

The sonde-derived vertical velocities were then filtered using a nine-point binomial smoother. This corresponds to altitudinal depths of $162-450 \mathrm{~m}$ assuming no missing data. Spurious data points outside of two standard deviations of the local mean in the nine-point filter were removed after smoothing was completed. The total dataset was reduced to 276515 data points and 437 sondes after all of the data restriction and removal were conducted.

Individual data points are used to create and analyze the vertical velocity frequency distributions, but were not considered to be independent updrafts or downdrafts in this study. Black et al. (1996) defined updrafts and downdrafts using Doppler radar data as consecutive, continuous vertical velocities exceeding $|1.5| \mathrm{m} \mathrm{s}^{-1}$ with at least one data point exceeding $|3| \mathrm{m} \mathrm{s}^{-1}$. The $|1.5| \mathrm{m} \mathrm{s}^{-1}$ threshold was chosen as it was outside the limits of uncertainty in the vertical incidence Doppler velocity and the $|3| \mathrm{m} \mathrm{s}^{-1}$ threshold was chosen as it was one standard deviation of hydrometeor fall speed above the limit of uncertainty (Black et al. 1996). Updrafts and downdrafts in this study were similarly defined as consecutive, continuous vertical velocities exceeding |2| $\mathrm{m} \mathrm{s}^{-1}$ (limit of uncertainty, see the appendix) with at least one data point exceeding $|4| \mathrm{m} \mathrm{s}^{-1}$ (one standard deviation of the vertical velocity above the limit of uncertainty). (a)

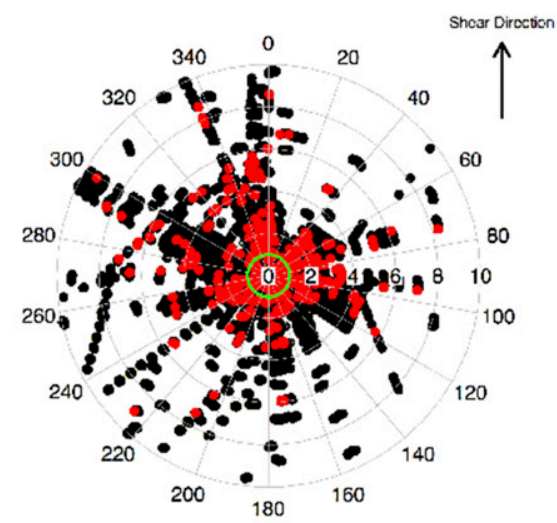

(c)

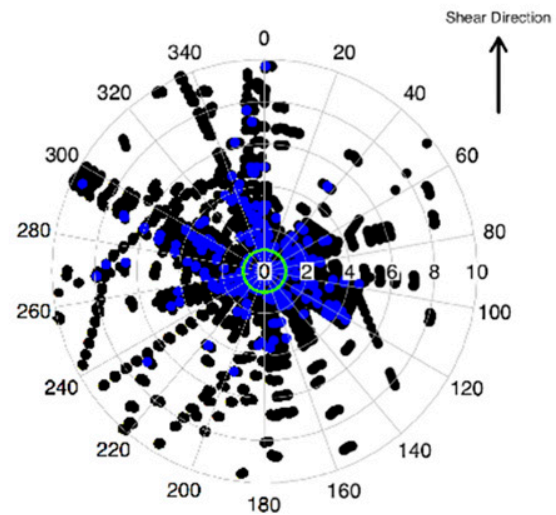

(b)

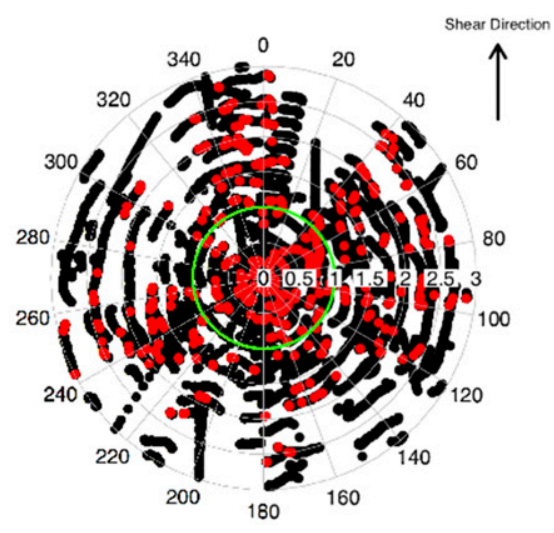

(d)

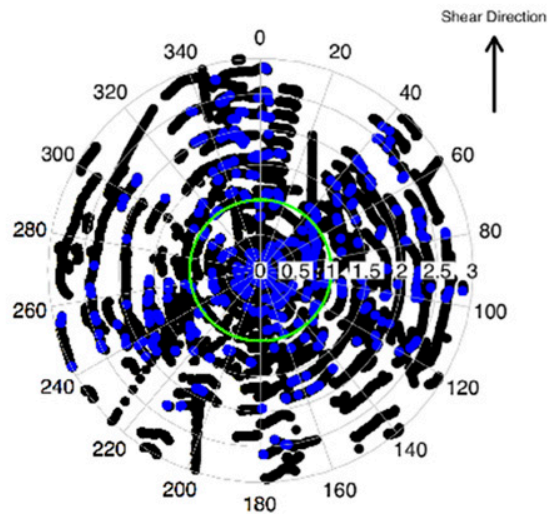

FIG. 3. Distribution of data points in the total dataset in a shear-rotated framework. Azimuth is in degrees and radius is the radius divided by the RMW $\left(R^{*}\right)$. The RMW is the green ring. (a),(c) Plotted out to $10 R^{*}$, and (b),(d) plotted out to $3 R^{*}$. Continuous positive vertical velocities within updrafts are in red in (a),(b) and continuous negative vertical velocities within downdrafts are in blue in (c),(d). 
TABLE 2. Mean, median, and standard deviation of vertical velocity in $\mathrm{m} \mathrm{s}^{-1}$ for all radii, within the core, and outside of the core.

\begin{tabular}{lccc}
\hline \hline Section & Mean & Median & Std dev \\
\hline $0-10 R^{*}$ & 0.20 & 0.00 & 1.43 \\
$0-3 R^{*}$ & 0.30 & 0.06 & 1.74 \\
$3-10 R^{*}$ & 0.09 & -0.04 & 0.98 \\
\hline
\end{tabular}

\section{b. Calculation of storm center and RMW}

The storm center was calculated using an iterative method similar to the methodologies of Creasey and Elsberry (2017) and Willoughby and Chemlow (1982) to find an estimated XDD-derived zero-wind center (ZWC). The dropsonde horizontal winds were put into a storm-relative framework by subtracting the $u$ and $v$ components of TC motion from the horizontal wind components. The TC motion was calculated by taking 6-h centered differences about the closest (in time) Automated Tropical Cyclone Forecast (AFTC) best track center from NHC.

A single ZWC was found by constructing orthogonal lines to the storm-motion-relative horizontal wind vectors at all altitudes. Weighted means of the intersecting independent $(x, y)$ coordinates from pairs of observations yield a single ZWC estimate and corresponding time for the depth of the troposphere. The weighting function was
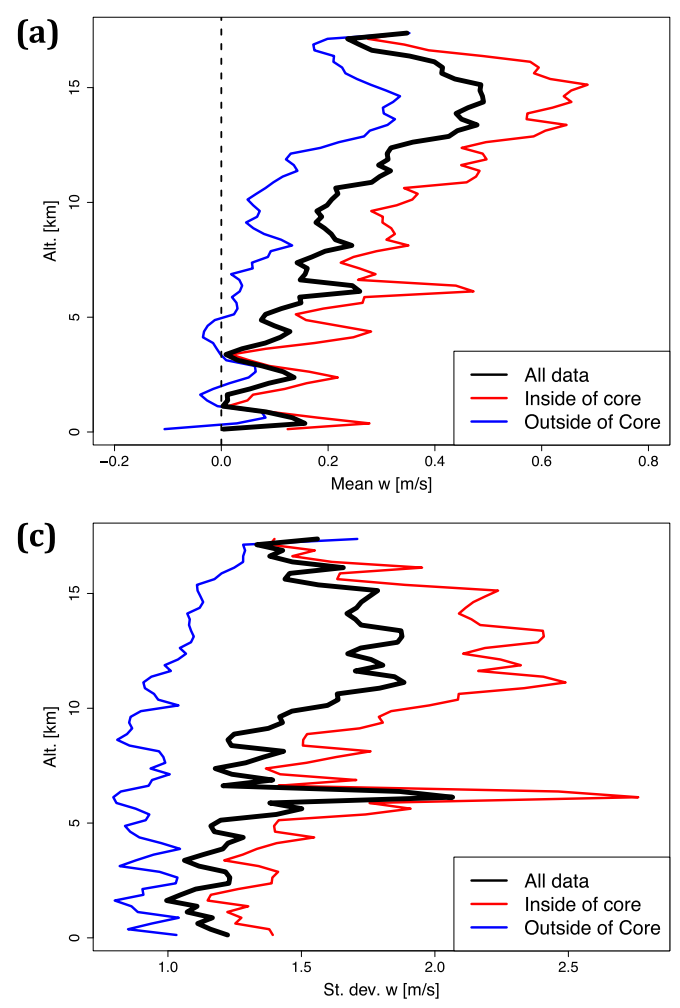

$$
W=\frac{V_{t}}{\left(r^{2}\right)},
$$

where $W$ is the weight for a given intersection, $V_{t}$ is the mean storm-motion-relative horizontal wind speed for any observation pair, and $r$ is the mean radial distance of the observation pairs to the previous TC center estimate at the time of the observations. The initial ZWC estimate was taken to be the NHC best track center, linearly interpolated to the minute. As a consequence of the weighting-function dependence on the ZWC estimate, Eq. (8) must be iterated to convergence. Iteration was done until the ZWC latitude and longitude converged on a single $\mathrm{ZWC}$ solution within $0.001^{\circ}$ (approximately $100 \mathrm{~m}$ ). All solutions converged within 18 iterations. The final ZWC is a single $\mathrm{ZWC}$ representative of the time of the observation with the highest weight. The final ZWC was also linearly interpolated to each minute of the observation period.

Rather than the traditional flight-level RMW, an estimated radius of maximum horizontal wind speed below an altitude of $2 \mathrm{~km}$ was calculated from the XDD horizontal wind data. The XDD-derived RMW was obtained by examining the strongest $99.98 \%$ of horizontal winds below $2 \mathrm{~km}$ and within a $100 \mathrm{~km}$ radius of the TC center. The RMW was approximated to be the mean radial distance of these relatively fast wind data points, rather

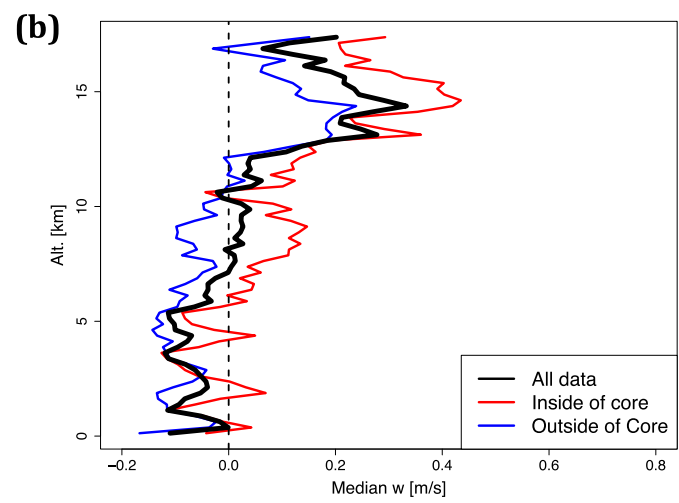

FIG. 4. (a) Mean, (b) median, and (c) standard deviation profiles of vertical velocity for the full dataset (black), data within the core (red), and data outside of the core (blue). The dashed black line designates $w=0 \mathrm{~m} \mathrm{~s}^{-1}$. 

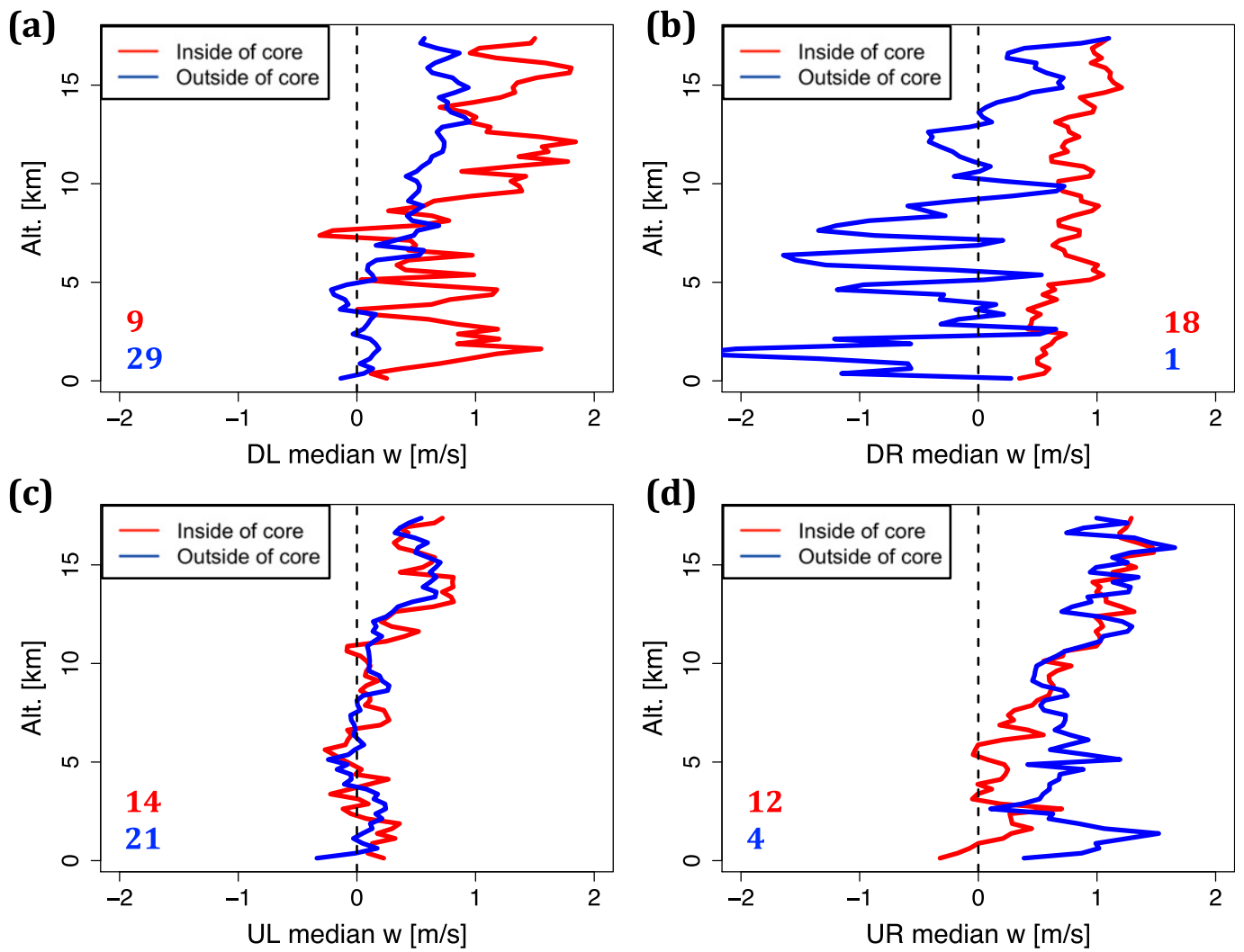

FIG. 5. Median vertical velocity profiles for data within the core (red) and outside of the core (blue) and within the (a) DL, (b) DR, (c) UL, and (d) UR quadrants in Marty. The dashed black line designates $w=0 \mathrm{~m} \mathrm{~s}^{-1}$. The approximate number of soundings in each quadrant is provided for within the core (red) and outside of the core (blue).

than a single data point maximum. This averaging was done because a single data point may be unrepresentative of the true horizontal wind field of the TC, may be artificially strong due to turbulence or noise, or may not be appreciably different than other horizontal wind measurements at other radii. The $99.98 \%$ percentile was chosen iteratively to exclude secondary wind maxima within $100 \mathrm{~km}$ of the centers of the three TCs. The number of data points used to derive the RMW ranged from one to eight for each observation day, with most days having greater than five data points, corresponding to one to three soundings for each observation day with most days having only one RMW sounding.

An RMW was also calculated from overpasses of the Hurricane Imaging Radiometer (HIRAD; Cecil et al. 2016) as the radius with the strongest observed wind speed. For the HIRAD RMWs, the TC center was taken to be the ZWC linearly interpolated to match the approximate center crossing, except for Joaquin. The ZWCs for Joaquin in this study, and in Creasey and Elsberry (2017), differ from the HIRAD estimated center by approximately $5-7 \mathrm{~km}$, potentially due to tilt of the TC. To alleviate this issue, the estimated HIRAD centers noted in Creasey and Elsberry (2017) were used to derive the HIRAD RMWs for Joaquin. Throughout the rest of the study, the RMWs used are the closest RMWs (derived from both the XDD data and the HIRAD data) to the best track dataset.

The well-documented, high-resolution, flight-level RMWs and Hurricane Research Division (HRD) centers were not used in this study because the flight-level data were rarely coincident with the TCI missions and HRD centers were not available for three of the ten observation days. Comparisons of the flight-level RMWs and HRD centers to the RMWs and ZWCs used in this study is provided as supplemental material, but the centers agree within a mean of approximately $17 \mathrm{~km}$, the RMWs agree within a mean of 8-9 km, and the use of the flight-level RMWs and HRD centers do not produce statistically different results for the seven days of coverage.

\section{c. Vertical wind shear}

The 1800 UTC environmental shear was obtained from the Statistical Hurricane Intensity Prediction 

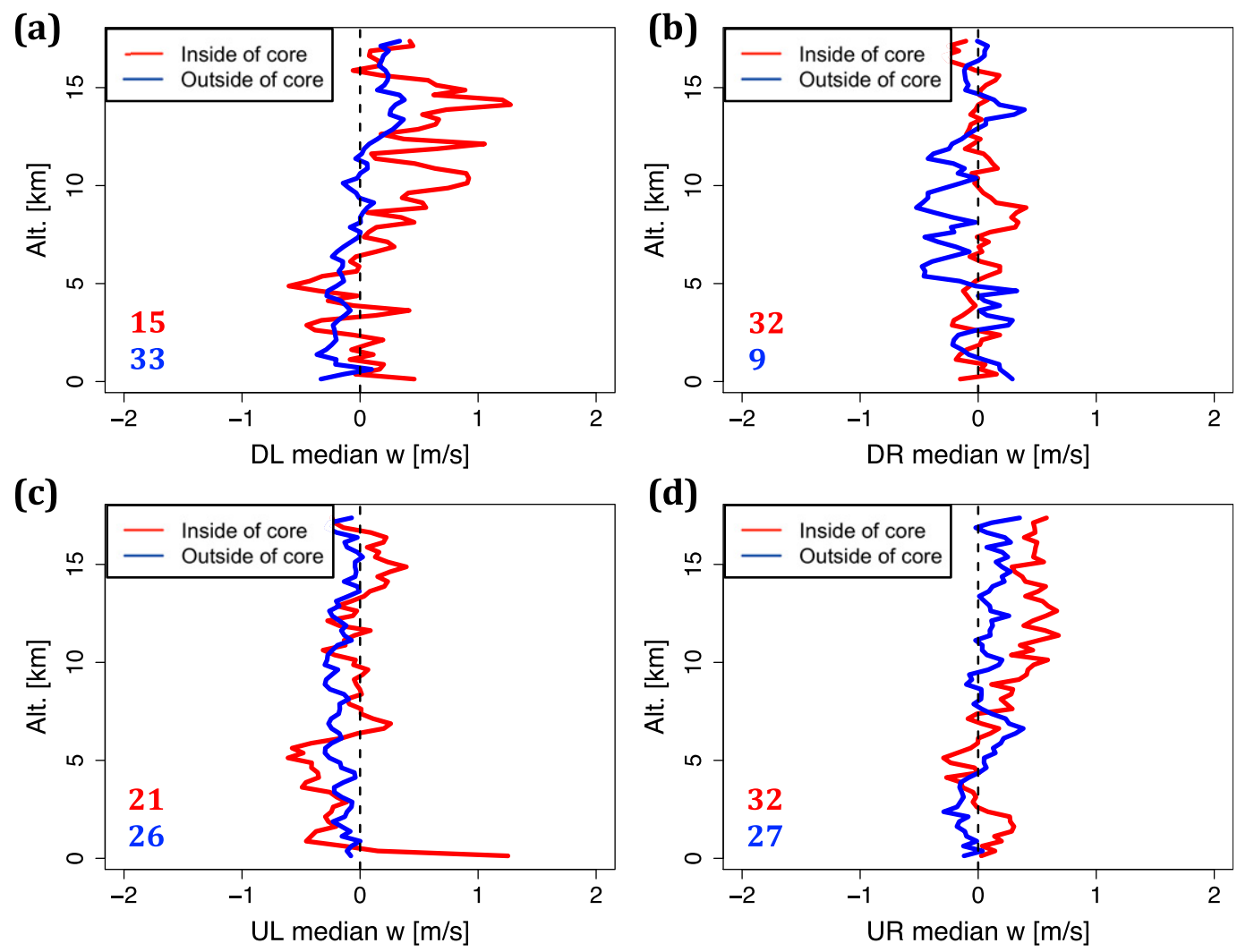

FIG. 6. As in Fig. 5, but for Joaquin.

Scheme (SHIPS) dataset (DeMaria and Kaplan 1994), as all flights were conducted near 1800 UTC. Data points were then analyzed in a "shear relative" framework. Here, shear is defined conventionally (e.g., DeMaria and Kaplan 1994) as the 850-200-hPa magnitude and direction with the vortex removed, and averaged from 0 to $500 \mathrm{~km}$ relative to the $850-\mathrm{hPa}$ vortex center.

\section{Results}

Summarized in Table 1 is the number of viable sondes for each day in the full dataset. Also given are storm diagnostics including shear and intensity from the best track dataset. As can be seen in Table 1, the dataset contained a strongly sheared case (Marty), a moderately sheared case (Joaquin), and a weakly sheared case (Patricia). Joaquin was an Atlantic hurricane, while Marty and Patricia were in the eastern North Pacific. Most of the observation periods had a component of westerly shear and only Patricia on 21 October had easterly shear. It is also evident that the number of sondes after data exclusion was distributed evenly from day to day, except for 20 and 23 October.
Figure 3 shows the individual vertical velocity data points in a shear-relative framework within $10 R^{*}$ and $3 R^{*}$. The downshear-right (DR) quadrant had the fewest observations: only $20 \%$ of the total vertical velocity data points. The upshear-right (UR) and upshear-left (UL) quadrants contained almost half of the data with $26 \%$ and $24 \%$ of the vertical velocity data points, respectively. The downshear-left (DL) contained $30 \%$. Even though the majority of observations were outside of the RMW (approximately $80 \%$ ), the area of the TC within the RMW had the highest number of data points per unit area, approximately 50 times more data points per unit area than outer radii (outside of $3 R^{*}$ ). In this study, we define all data within $3 R^{*}$ as the core following Rogers et al. (2013). Approximately 49\% of the data were inside of the core.

\section{a. Vertical profiles of vertical velocity}

The mean vertical velocity values for the cores and outside of the cores of the three TCs agree well with the mean Doppler-derived vertical velocities for the eyewall and stratiform regions examined by Black et al. (1996) (Table 2). Mean, median, and standard deviation profiles of vertical velocity for all of the 

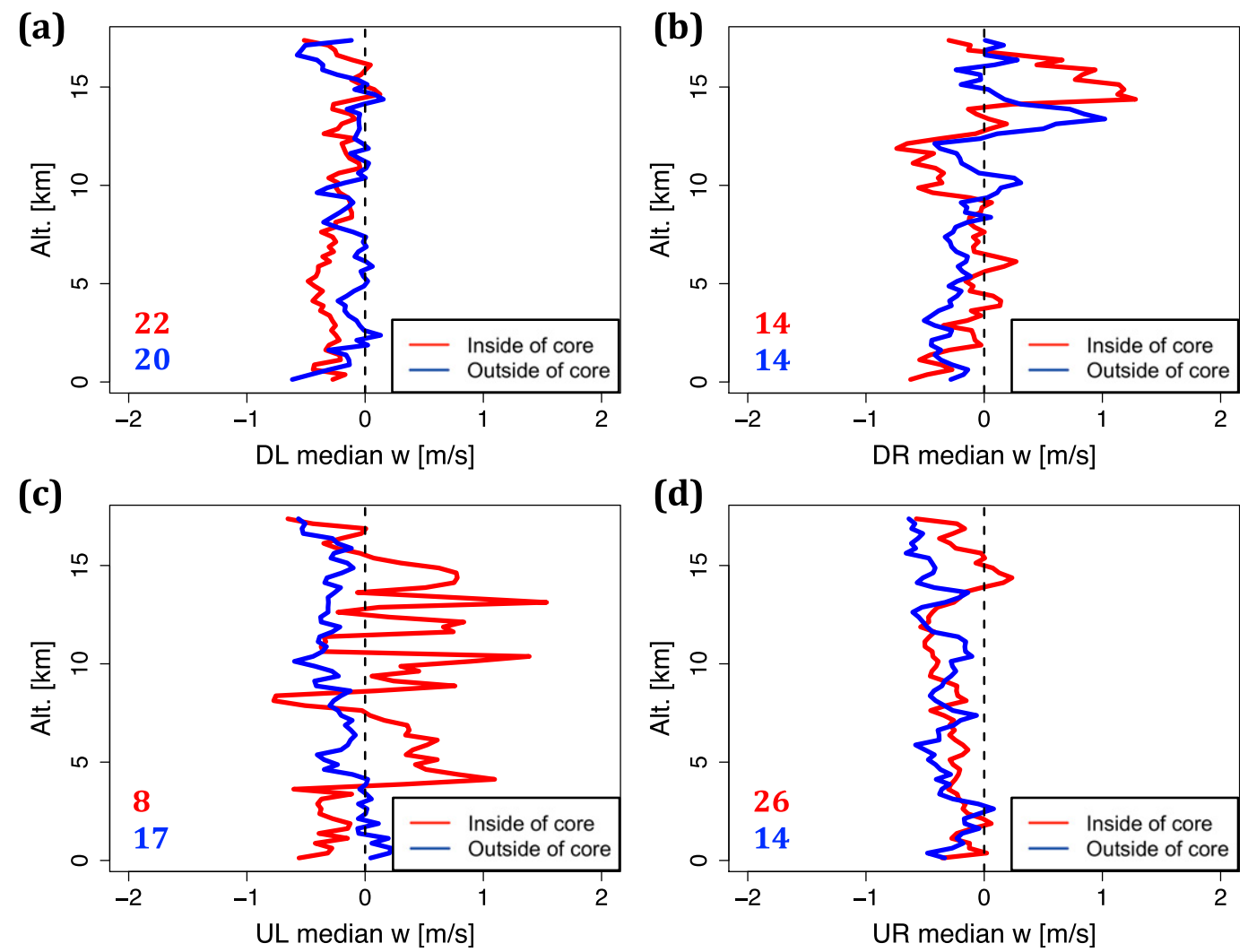

FIG. 7. As in Fig. 5, but for Patricia.

data, within the core, and outside of the core are provided in Fig. 4. The mean profiles in vertical velocity for data inside and outside of the core also agree well with the Doppler vertical velocity profiles observed for the eyewall and stratiform regions in Black et al. (1996).

The median vertical velocity profiles were weaker than the mean vertical velocity profiles, but similar structures exist (Figs. 4a,b). The strongest vertical velocities were found aloft and within the core in both profiles (Figs. 4a,b), in agreement with the Doppler profiles observed by Black et al. (1996) despite XDD-derived vertical velocity errors increasing with altitude (see appendix). Vertical velocities were positive for much of the depth of the troposphere, but some negative vertical velocities were found below $5 \mathrm{~km}$ in the mean profile for data outside of the core (Fig. 4a), below $10 \mathrm{~km}$ in the median profile for data outside of the core (Fig. 4b), and below $5 \mathrm{~km}$ in the median profile for data within the core (Fig. 4b).

There was a notable peak in mean vertical velocity strength and standard deviation within the core just above the approximate freezing level at $5-6 \mathrm{~km}$ (Figs. 4a,c). It is not known if this spike is physically significant (e.g., Black et al. 1996; Heymsfield et al. 2010) or instrumentation errors due to icing. Regardless, the standard deviation of the vertical velocity was largest within the core, but fairly constant for data outside the core below $10 \mathrm{~km}$ (Fig. 4c).

Figures 5-8 show median vertical velocity profiles both inside (red) and outside (blue) of the core and within each shear-relative quadrant for Marty, Joaquin, Patricia, and for the total dataset. The approximate number of soundings within the core and outside of the core in each quadrant is also provided. These numbers are approximate because some soundings crossed quadrant boundaries. In those situations, the sounding was classified in the quadrant where it had the most data points. Statistical differences or statistical significances of the vertical velocity strength cannot be inferred directly from the median profiles, but they do agree well with bootstrap analysis and significance tests of the median vertical velocities (see supplemental material). Mean profiles (not shown) show similar results as the median profiles.

Marty had large amplitude and noisy median vertical velocity profiles within the core in the DL quadrant and outside of the core in the DR quadrant (Fig. 5). This is 

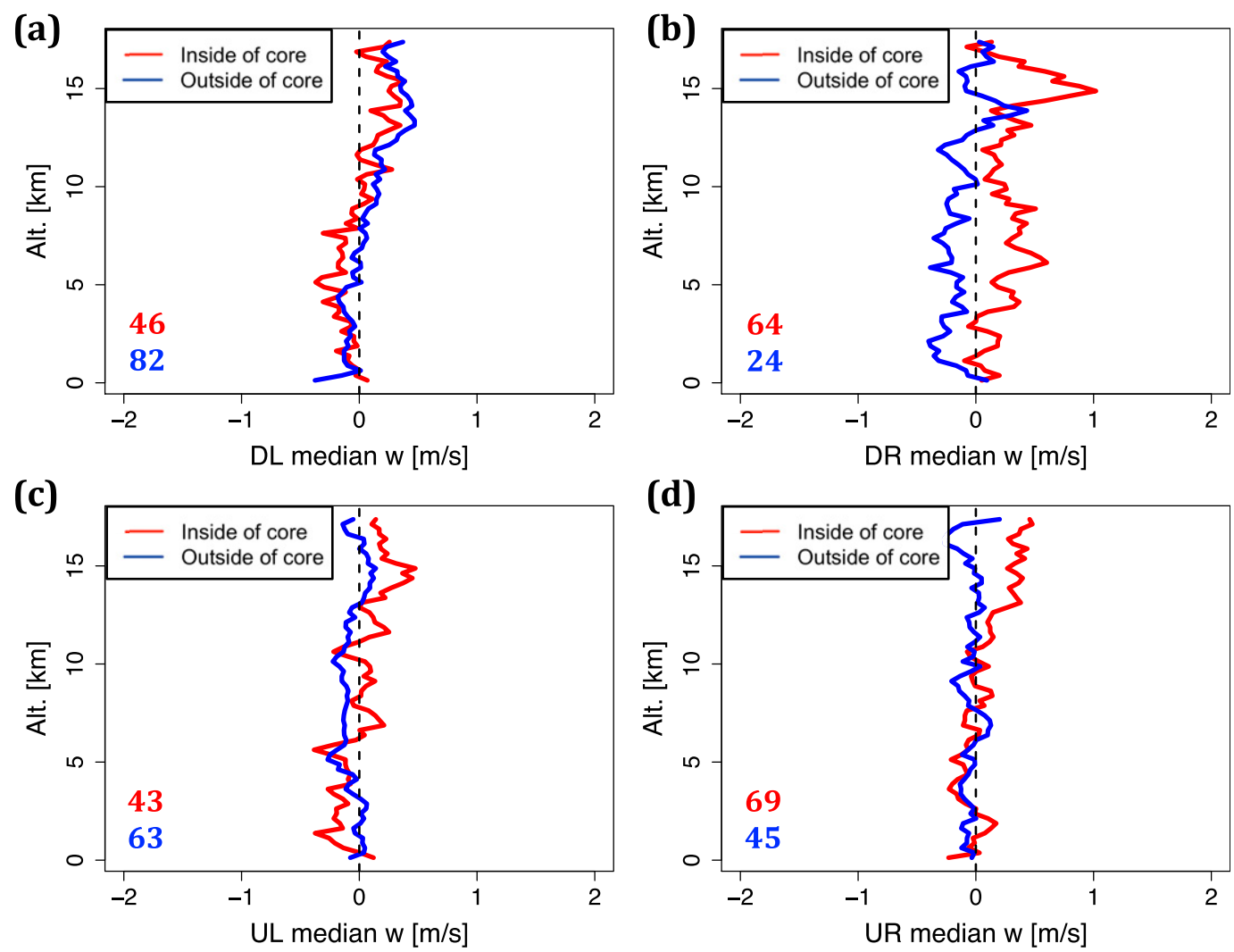

FIG. 8. As in Fig. 5, but for the total dataset.

likely a result of vertical variations in the vertical velocity data and a lack of samples (nine soundings and one sounding, respectively). The upshear profiles within the core and outside of the core are consistent and similar to each other, with the weakest median vertical velocity profiles in the UL quadrant (Fig. 5). Joaquin had stronger and more positive median vertical velocity profiles in the DL and UR quadrants within the core above $6 \mathrm{~km}$, and strong low-level positive vertical velocities in the left-of-shear quadrants within the core, especially the UL quadrant (Fig. 6). Patricia had strong upper-level positive vertical velocities in the DR quadrant, while the median vertical velocity profiles in the UR and DL quadrants were primarily weak and negative (Fig. 7). Similar to Marty, Patricia had a noisy vertical velocity profile within the core in the UL quadrant (Fig. 7), caused by three soundings near the eye that had strong variations in vertical velocity about zero. The combined dataset features positive upper-level vertical velocities above $7.5 \mathrm{~km}$ in the DL quadrant and negative vertical velocities below; positive vertical velocities below $13 \mathrm{~km}$ within the core in the DR quadrant; negative vertical velocities below $13 \mathrm{~km}$ outside of the core in the DR quadrant; and, generally, weaker median vertical velocity profiles in the upshear quadrants (Fig. 8).

\section{b. Contoured frequency diagrams}

Contoured frequency diagrams with respect to radius (CFRD), shear-relative (SR) azimuth (CFAzD), and altitude (CFAD) are used to examine the XDD-derived vertical velocity distributions from TCI (Figs. 9-11). The contoured frequency plots were created for each TC as well as for the total dataset, with an altitudinal bin size of $250 \mathrm{~m}$, a radial bin size of $0.5 R^{*}$, and an azimuthal bin size of $10^{\circ}$. The bin sizes were chosen iteratively and subjectively. The vertical velocities were binned every $1 \mathrm{~m} \mathrm{~s}^{-1}$. Because of the shear-relative and radial biases in sampling, the contoured frequency plots are displayed as contoured percent diagrams, with a logarithmic scale. All percentages within any given bin (radial, azimuth, or altitudinal) sum to $100 \%$. For reference, black horizontal lines in the contoured frequency diagrams denote the vertical velocity thresholds used to define updrafts and downdrafts $\left(|2| \mathrm{m} \mathrm{s}^{-1}\right.$ and $\left.|4| \mathrm{ms}^{-1}\right)$.

The peak vertical velocity strength generally decreased with increasing radius, and the radial distribution shows that positive vertical velocities more frequently 
(a)

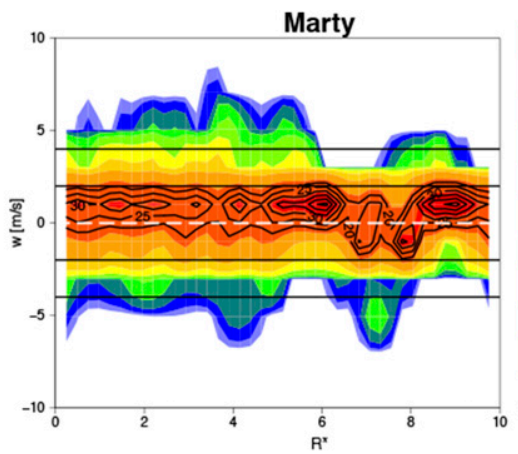

(c)

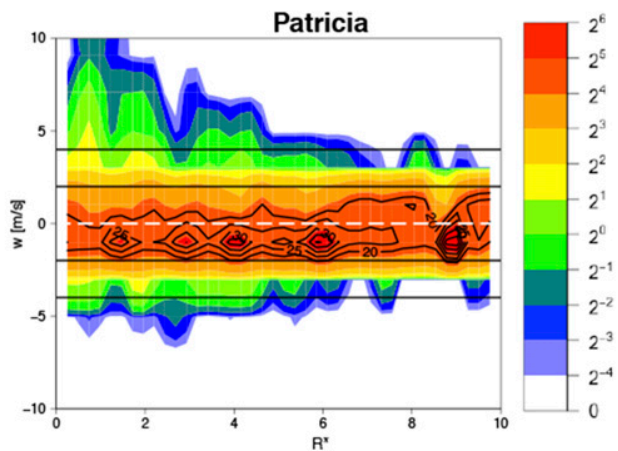

(b)

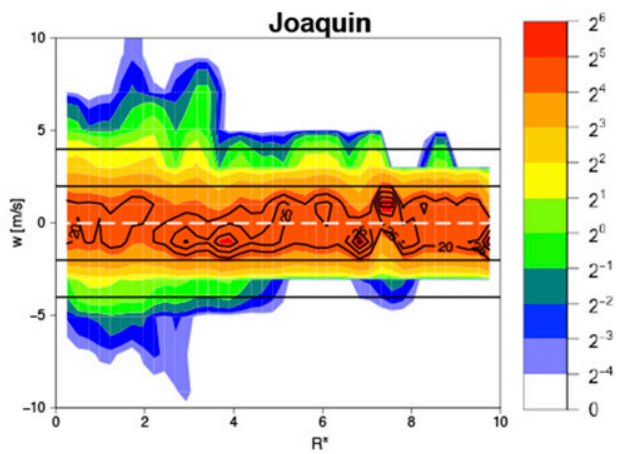

(d)

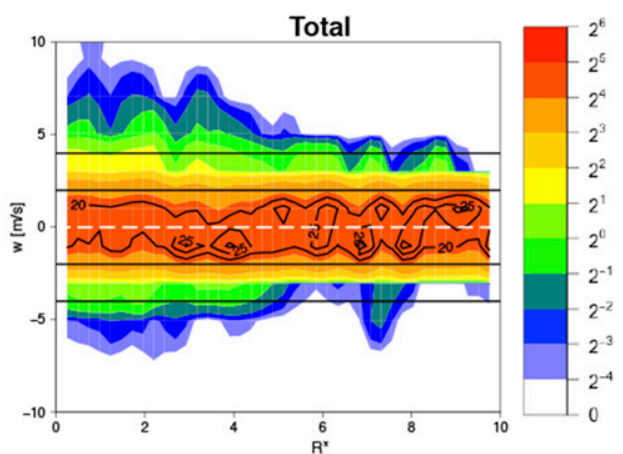

FIG. 9. CFRD percentages of vertical velocities $\left(\mathrm{m} \mathrm{s}^{-1}\right.$ ): (a) Marty, (b) Joaquin, (c) Patricia, and (d) the entire dataset. Colored contours are percentages on a logarithmic scale. Black lined contours are percentages above $20 \%$ in intervals of $5 \%$. The horizontal solid black lines denote the vertical velocity thresholds. The dashed white line designates $w=0 \mathrm{~m} \mathrm{~s}^{-1}$.

exceeded the updraft thresholds than negative vertical velocities for the downdraft thresholds (Fig. 9d). The decrease in vertical velocity strength with increasing radius was not as prominent in Marty (Fig. 9a) as it was in Joaquin and Patricia (Figs. 9b,c). It should be noted, however, that negative vertical velocity magnitudes were much weaker than positive vertical velocity magnitudes, especially in Patricia (Fig. 9c) and exhibited less of a decrease in strength with increasing radius. Joaquin and Patricia had similar vertical velocity frequency distributions radially, especially for positive vertical velocities (Figs. 9b,c). Both TCs also had vertical velocity data points that exceeded $10 \mathrm{~m}^{-1}$, which occurred at the RMW in Patricia and at approximately $3.5 R^{*}$ in Joaquin (not shown in the CFRDs).

For all storms and all radii (Fig. 10d), there was little azimuthal variation in the observed vertical velocity distribution, but the strongest vertical velocities were primarily observed in the right-of-shear quadrants. The lack of azimuthal variation in the vertical velocity distribution could be attributed to the relatively small sample size of three TCs or the asymmetric sampling during TCI (Fig. 3). The CFAzD for Marty (Fig. 10a) shows little azimuthal variation in the strongest negative vertical velocities, with most of the variation in the distribution occurring within the vertical velocity uncertainty bounds. The strongest positive vertical velocities in the distribution, however, were observed in the left-of-shear quadrants, especially the DL quadrant (Fig. 10a). The vertical velocity distributions of Joaquin and Patricia also show little systematic azimuthal variation (Figs. 10b,c), with sporadic peaks in frequency at different vertical velocity values. There was a decrease in the vertical velocity strength, and frequency of vertical velocities above the updraft, and downdraft, thresholds in the upshear quadrants of Patricia (Fig. 10c).

The CFADs for all radii for each TC and the combined dataset are shown in Fig. 11. Vertical velocity in the combined dataset was a weak function of altitude, with Fig. 11d showing that the vertical velocity distribution broadens slightly aloft and becomes skewed toward larger, more positive values. There was little altitudinal variation in the CFAD for Marty, but the distribution was skewed toward positive vertical velocities, and there were higher frequencies of negative vertical velocity below $5 \mathrm{~km}$ (Fig. 11a). The altitudinal vertical velocity distribution in Joaquin was more centered around zero than in Marty, but high percentages of negative values of approximately $-1.5 \mathrm{~m} \mathrm{~s}^{-1}$ were present in Joaquin (Fig. 11b). Positive vertical velocities 
(a)

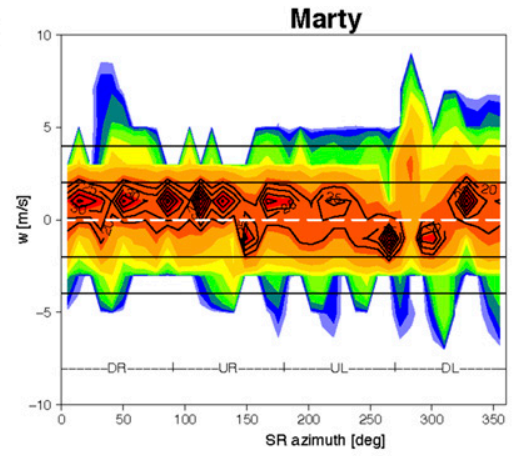

(c)

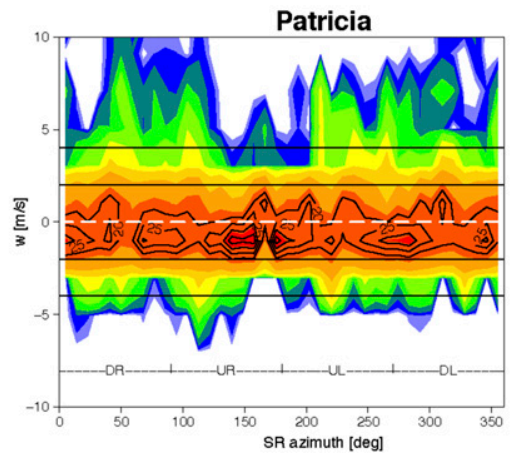

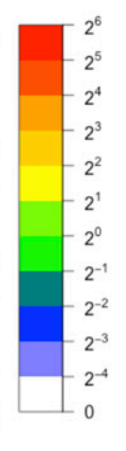

(b)

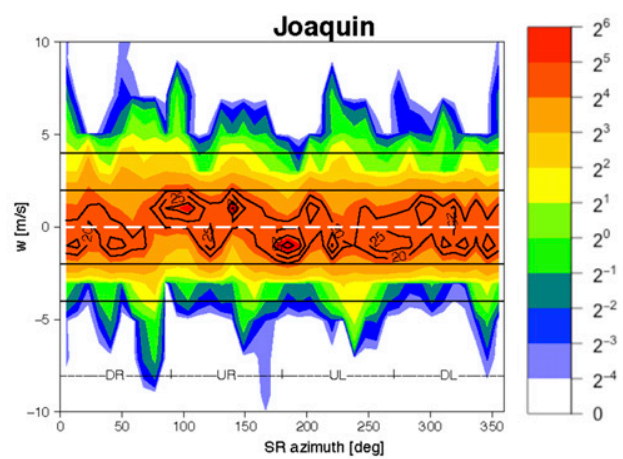

(d)
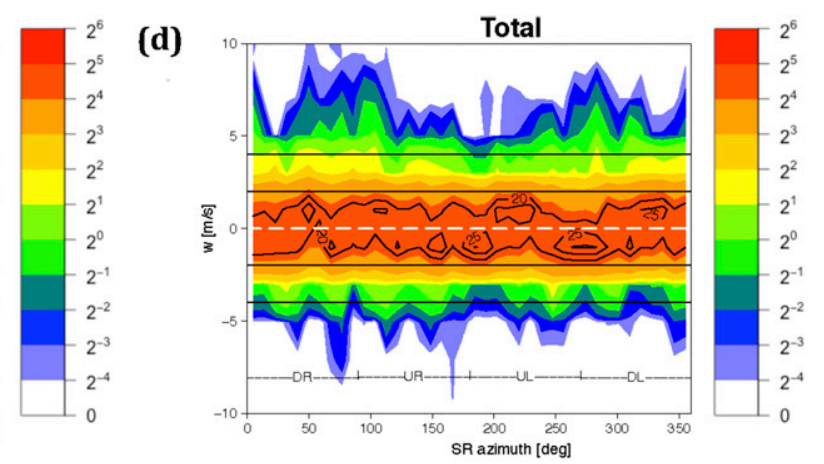

FIG. 10. CFAzD percentages of vertical velocities $\left(\mathrm{m} \mathrm{s}^{-1}\right.$ ): (a) Marty, (b) Joaquin, (c) Patricia, and (d) the entire dataset. Colored contours are percentages on a logarithmic scale. Black lined contours are percentages above $20 \%$ in intervals of $5 \%$. The horizontal solid black lines denote the vertical velocity thresholds. The dashed white line designates $w=0 \mathrm{~m} \mathrm{~s}^{-1}$.

in Joaquin weakly increased in strength aloft and negative vertical velocities were fairly uniform with altitude (Fig. 11b). Patricia had a different altitudinal vertical velocity distribution than Marty or Joaquin (Fig. 11c). The CFAD for Patricia shows that vertical velocity was skewed toward negative values, especially within the uncertainty bounds, but there was more spread in the positive values and little altitudinal signal (Fig. 11c).

CFRDs, CFAzDs, and CFADs for data within the core and outside of the core are provided as supplemental material, but the results are summarized here. The CFAzDs and CFADs for data within the core are not appreciably different from the total CFAzDs and CFADs. The similarities between the contoured frequency diagrams for all radii and the contoured frequency diagrams from the core reflect that the cores of the TCs have the most variation and spread in the strength of the observed vertical velocities. The azimuthal distributions for all three TCs outside of the core have higher frequencies of lower vertical velocity strength, but little azimuthal variability exists in vertical velocity strength. There were very few data points outside of the core in the DR or UR quadrants in Marty and in the DR quadrant in Joaquin due to sampling biases, which makes the distribution outside of the cores in Marty and Joaquin not robust. The CFADs for data outside of the core generally showed narrower vertical velocity distributions and more negative vertical velocities than the total CFADs, with differing altitudes of peak vertical velocity strength.

\section{c. Updrafts and downdrafts}

Table 3 shows the number of updrafts and downdrafts (defined using the $|2| \mathrm{m} \mathrm{s}^{-1}$ and $|4| \mathrm{m} \mathrm{s}^{-1}$ thresholds; section 2a) observed in the soundings used in this study, as well as the means and medians of the maximum and minimum updraft and downdraft speeds. Given the small sample size of updrafts and downdrafts, robust conclusions about the convective asymmetries in the three TCs cannot be made, but the examination of the updrafts and downdrafts observed is useful in understanding the TCI vertical velocity dataset. Patricia had the strongest observed mean and median updraft speeds, the strongest peak updraft strength at $23.89 \mathrm{~m} \mathrm{~s}^{-1}$, and was the only TC to have a low-level updraft (below $2 \mathrm{~km}$ ) with a maximum value exceeding $10 \mathrm{~m} \mathrm{~s}^{-1}$. Downdraft speeds were more comparable between the three TCs, with the strongest downdraft in 
(a)

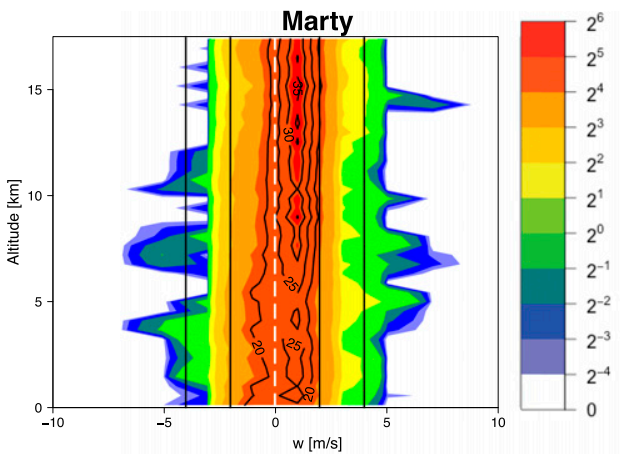

(c)

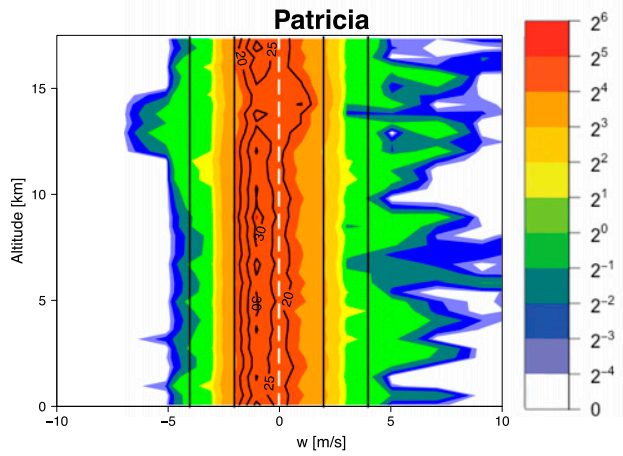

(b)

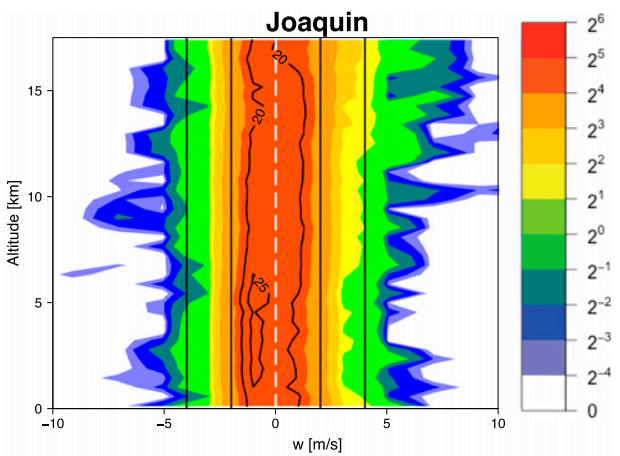

(d)

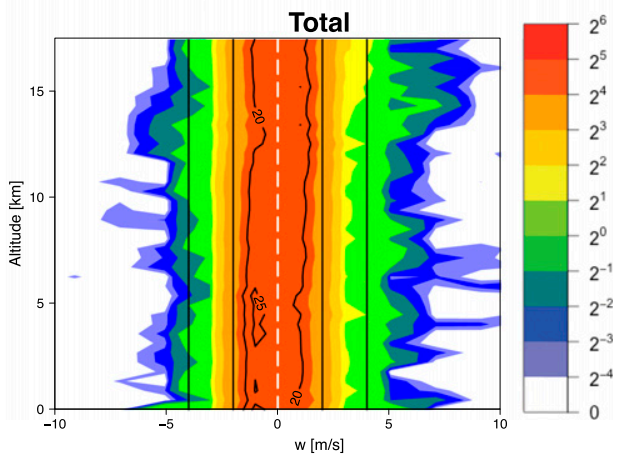

FIG. 11. CFAD percentages of vertical velocities ( $\mathrm{m} \mathrm{s}^{-1}$ ): (a) Marty, (b) Joaquin, (c) Patricia, and (d) the entire dataset. Colored contours are percentages on a logarithmic scale. Black lined contours are percentages above $20 \%$ in intervals of $5 \%$. The horizontal solid black lines denote the vertical velocity thresholds. The dashed white line designates $w=0 \mathrm{~m} \mathrm{~s}^{-1}$.

Joaquin at $-8.7 \mathrm{~m} \mathrm{~s}^{-1}$. Most updrafts and downdrafts observed during TCI had mean and median strengths of approximately $|3-4| \mathrm{m} \mathrm{s}^{-1}$, and maximum strengths of approximately $|4-5| \mathrm{m} \mathrm{s}^{-1}$. Updraft and downdraft depths were primarily less than $4 \mathrm{~km}$ with $50 \%$ of the updrafts and downdrafts smaller than 1.2-1.4 km.

Shown in Figs. 12-14 are select "cross sections" of vertical velocity with updrafts and downdrafts contoured. It is important to note that the cross sections presented here are not true cross sections, because the sondes drift around the TC in a cyclonic trajectory. Each data point corresponds to a unique altitude and distance from the center to account for radial drift of the sonde during descent. The horizontal and radial winds reported in Figs. 12-14 are storm-motion relative.

The strongest vertical velocities and updrafts in Marty on 27 September were aloft, above $12 \mathrm{~km}$ in the eyewall (inner $30-40 \mathrm{~km}$; Fig. 12). There were weaker bands of positive and negative vertical velocities outside of the eyewall to the northwest of the TC center (Fig. 12). Joaquin on 2 October was at a stronger intensity than Marty on 27 September and had considerably stronger and deeper eyewall updrafts than Marty at approximately $8 \mathrm{~m} \mathrm{~s}^{-1}$ (Fig. 13). Joaquin on 2 October also exhibited an asymmetric distribution in the eyewall convection (e.g., Fig. 13). The strongest eyewall convection was toward the southeast of TC center, which is on the downshear side of the storm (Fig. 13).

The vertical velocity cross section on 23 October in Patricia shows deep, strong low-level and midlevel eyewall updrafts greater than $10 \mathrm{~m} \mathrm{~s}^{-1}$ (Figs. 14a,b). Patricia also had a low-level updraft that exceeded

TABLE 3. Number of updrafts and downdrafts from each TC $(N)$ and the mean, median, and maximum/minimum of the peak updraft and downdraft strengths in $\mathrm{ms}^{-1}$.

\begin{tabular}{lrccc}
\hline \hline Name & $N$ & Mean & Median & Maximum \\
\hline \multicolumn{5}{c}{ Updrafts } \\
Marty & 17 & 5.11 & 4.90 & 7.23 \\
Joaquin & 48 & 5.91 & 5.11 & 18.33 \\
Patricia & 38 & 8.72 & 6.77 & 23.89 \\
Total & 103 & $6.58(\mathrm{avg})$ & $5.59(\mathrm{avg})$ & $16.48(\mathrm{avg})$ \\
& \multicolumn{5}{c}{ Downdrafts } \\
Name & $N$ & Mean & Median & Minimum \\
Marty & 9 & -5.15 & -5.16 & -5.90 \\
Joaquin & 24 & -5.40 & -4.81 & -8.70 \\
Patricia & 10 & -4.54 & -4.29 & -5.95 \\
Total & 43 & $-5.03(\mathrm{avg})$ & $-4.75(\mathrm{avg})$ & $-6.85(\mathrm{avg})$ \\
\hline
\end{tabular}


(a)

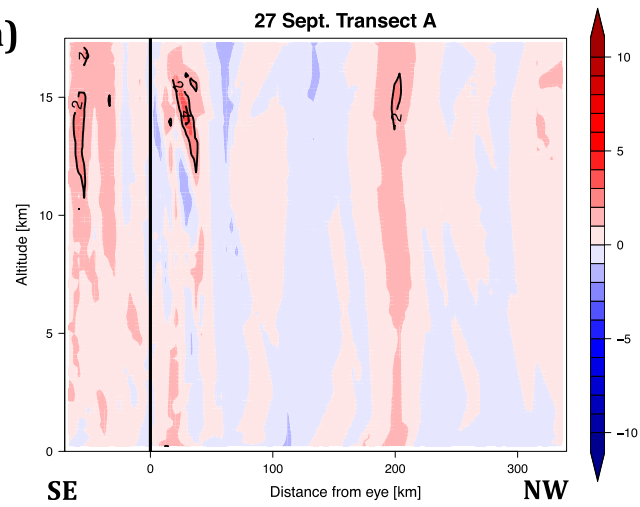

(b)

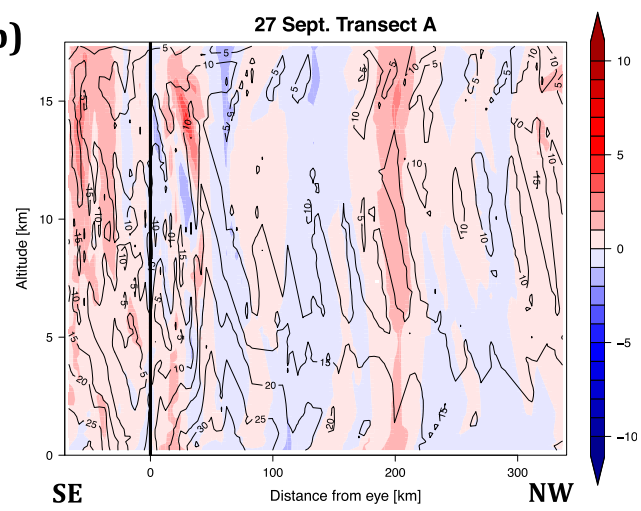

FIG. 12. Transect cross sections for Marty on $27 \mathrm{Sep}$ : (a) vertical velocity ( $\mathrm{m} \mathrm{s}^{-1}$, shaded) with vertical velocities greater than $|2| \mathrm{m} \mathrm{s}^{-1}$ contoured, and (b) vertical velocity $\left(\mathrm{m} \mathrm{s}^{-1}\right.$, shaded) and horizontal wind speed $\left(\mathrm{m} \mathrm{s}^{-1}\right.$, contoured). The TC center is denoted with a solid vertical black line. Note that the horizontal winds are stormmotion relative.

$10 \mathrm{~m} \mathrm{~s}^{-1}$ collocated with a localized azimuthal wind maximum (Fig. 14b) and apparent radial overturning circulation (Fig. 14c) in the vicinity of a secondary eyewall observed in HIRAD data (Fig. 15), which supports the numerical simulations by Hazelton et al. (2017). The low-level radial overturning circulation was sampled by six soundings spaced $5-11 \mathrm{~km}$ apart with small radial (approximately $18-300 \mathrm{~m}$ ) and azimuthal (approximately $1-2 \mathrm{~km}$ ) drifting below $2 \mathrm{~km}$. The spacing of the last data points of the soundings also did not deviate drastically from their spacing at $2 \mathrm{~km}$. The relatively small radial and azimuthal motions, and small spacing deviations of the soundings below $2 \mathrm{~km}$, do not severely impact the interpretation of the low-level cross section in Fig. $14 \mathrm{c}$ and indicates that the radial overturning circulation is real and not a manifestation of sounding issues. It cannot be concluded with absolute certainty, however, that the low-level radial circulation and the strong low-level updraft were directly associated with the secondary eyewall. The radial overturning circulation and low-level updraft were also collocated if the high-resolution HRD center was used instead of the

(a)

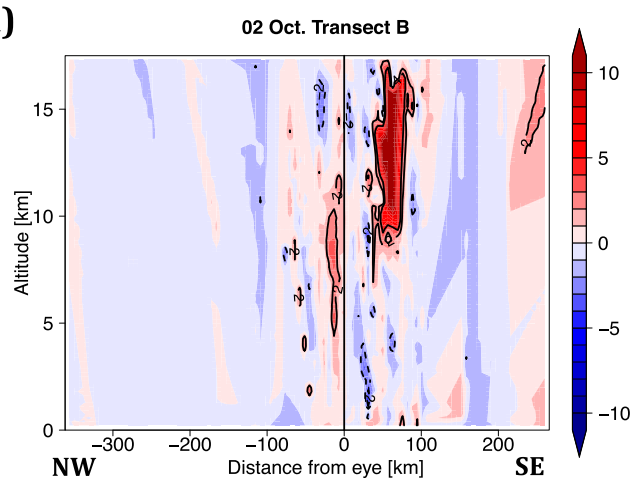

XDD-derived ZWC, which had a mean difference of $6 \mathrm{~km}$ on 23 October. This suggests that the presence of the radial overturning circulation in Fig. 14 is robust despite the differences between the two tracks.

Patricia also had a $\pm 2 \mathrm{~ms}^{-1}$ amplitude wave-like feature in the vertical velocity on 23 October near $17 \mathrm{~km}$ with a wavelength of approximately $20-30 \mathrm{~km}$. This apparent wavelike feature is in the same approximate location to where Duran and Molinari (2018) found a potential gravity wave at a comparable wavelength (Figs. 14d,e). The potential gravity wave is visible in both pressure (Fig. 14d) and potential temperature (Fig. 14e) at a wavelength of $20-30 \mathrm{~km}$. The agreement between both studies, and the agreement between the wavelike feature in the vertical velocity, pressure, and potential temperature, further supports that the XDDs sampled a gravity wave in Patricia on 23 October.

\section{Discussion}

Examining the altitudinal, azimuthal, and radial frequency distributions of vertical velocity, as well as the

(b)

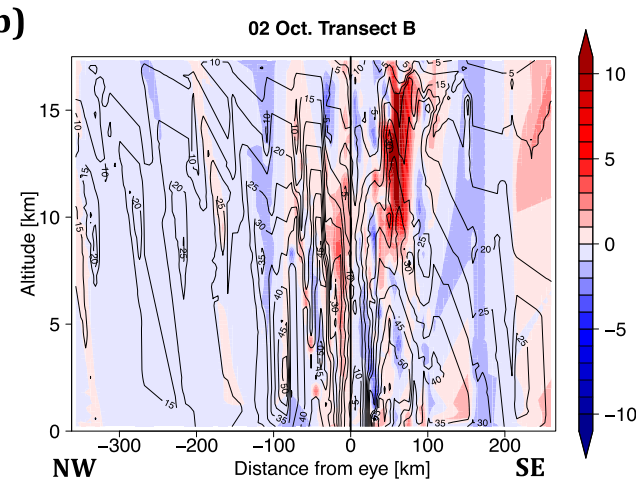

FIG. 13. As in Fig. 12, but for Joaquin on 2 Oct. 
(a)

(a)

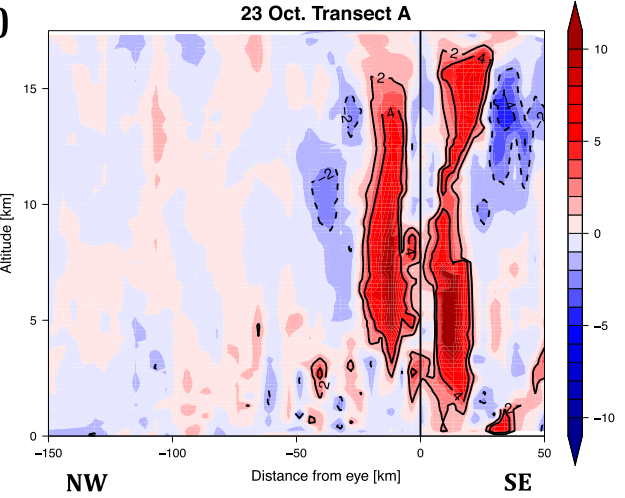

(c)

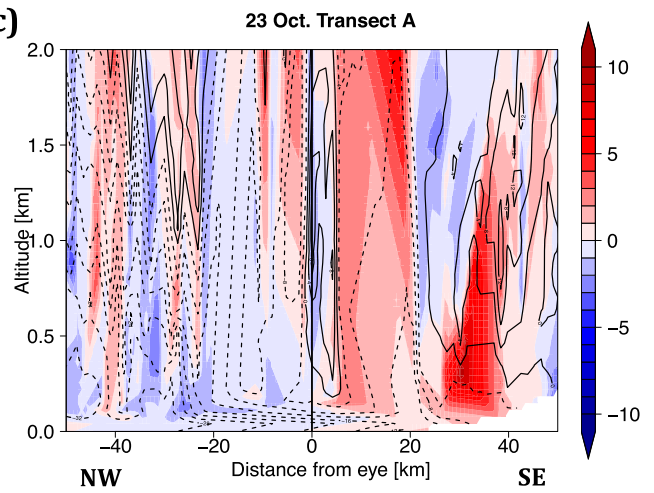

(e)

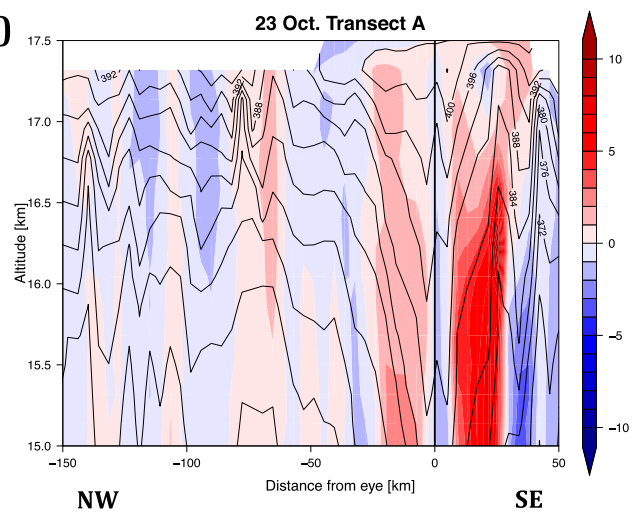

(b)

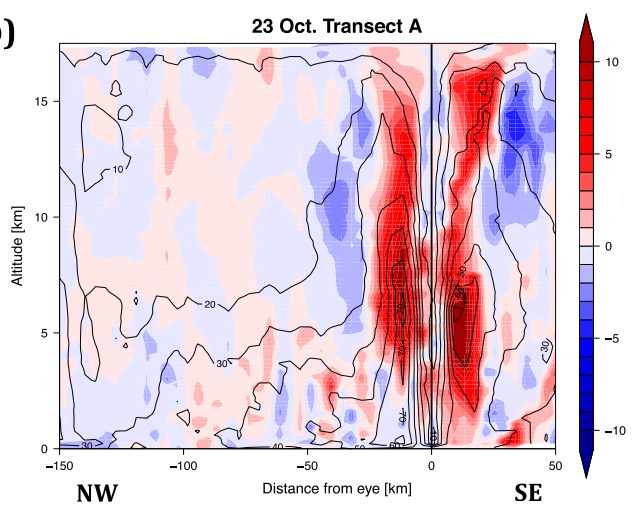

(d)

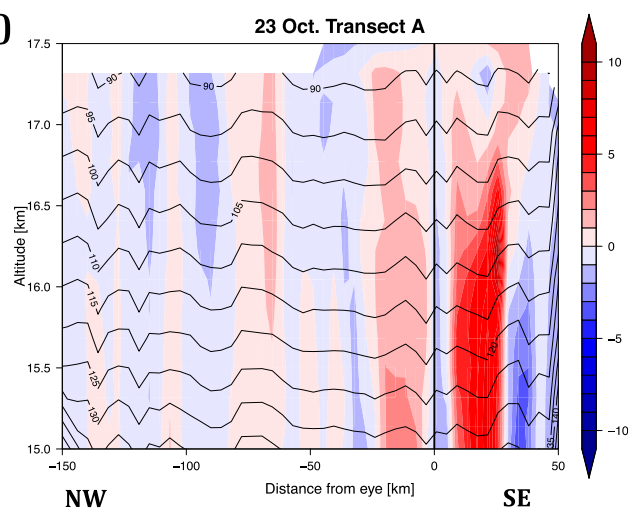

FIG. 14. Transect cross section for Patricia on 23 Oct: (a) vertical velocity $\left(\mathrm{m} \mathrm{s}^{-1}\right.$, shaded), with vertical velocities greater than $|2| \mathrm{m} \mathrm{s}^{-1}$ contoured, (b) vertical velocity ( $\mathrm{m} \mathrm{s}^{-1}$, shaded) and horizontal wind speed ( $\mathrm{m} \mathrm{s}^{-1}$, contoured), (c) low-level zoomin of (a) showing vertical velocity $\left(\mathrm{m} \mathrm{s}^{-1}\right.$, shaded) and radial velocity $\left(\mathrm{m} \mathrm{s}^{-1}\right.$, contoured), where inflow is negative and outflow is positive, (d) an upperlevel zoom-in of (a) for vertical velocity $\left(\mathrm{m} \mathrm{s}^{-1}\right.$, contoured) and pressure (hPa, contoured), and (e) an upper-level zoom-in of (a) for vertical velocity ( $\mathrm{m} \mathrm{s}^{-1}$, contoured) and potential temperature ( $\mathrm{K}$, contoured). Note that the horizontal and radial winds are storm-motion relative. strength of the vertical velocity, serves a critical role in understanding the kinematic and convective environments of the TCs observed during TCI. The results presented here are a preliminary step at evaluating sonde-derived vertical velocities from the XDDs in TCs. The unprecedented high temporal and spatial resolution of these sondes during TCI allowed for analysis of the vertical velocities in Marty, Joaquin, and Patricia. These results serve as documentation of the strength and location of vertical velocities observed during TCI.

From the large datasets of RD-93 and RD-94 data, it has been shown that low-level $(<3 \mathrm{~km})$ updrafts greater than $10 \mathrm{~m} \mathrm{~s}^{-1}$ occur exclusively in major hurricanes (Stern et al. 2016). Out of the 437 sondes (276515 data points) used in this study, only 719 vertical data points had vertical velocities greater than $10 \mathrm{~m} \mathrm{~s}^{-1}(0.3 \%$ of the data), only 12 unique updrafts had maximum vertical velocities greater than $10 \mathrm{~m} \mathrm{~s}^{-1}$, and only two of the positive vertical velocity data points below $3 \mathrm{~km}$ reached $10 \mathrm{~m} \mathrm{~s}^{-1}$. The two data points were within a low-level updraft with collocated horizontal winds of $42 \mathrm{~m} \mathrm{~s}^{-1}$ and an overturning circulation in Patricia on 23 October as a major hurricane, but during rapid weakening (Figs. 14 and 15). At the same time, a potential upper-level gravity wave was observed in the vertical velocity, pressure, and potential temperature fields (Fig. 14). The strongest downdrafts, however, were not observed in Patricia, but in Joaquin. 


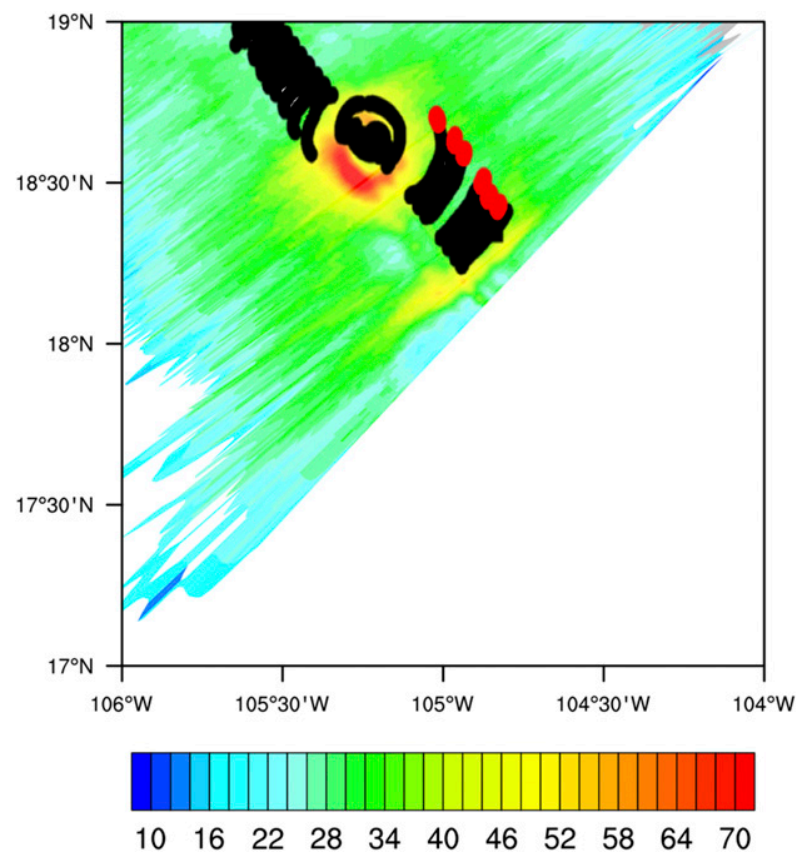

FIG. 15. HIRAD-derived horizontal wind speeds for a transect over the center of Patricia on 23 Oct. Sounding trajectories are plotted in black and data points that sampled the low-level radial circulation are plotted in red.

The results of this study show that vertical velocity strength, updraft strength, and downdraft strength are all strongest within the core (Figs. 4-9), which is also supported by comparisons of CFADs and CFAzDs for data within the core and outside of the core (see supplemental material). Evidence of stronger, positive mean and median vertical velocities were also found aloft for the entire dataset and within most shear quadrants in all three TCs (Figs. 4-8), which agrees with the findings of Black et al. (1996), Black et al. (2002), Heymsfield et al. (2010), Reasor et al. (2013), and DeHart et al. (2014) that utilized flight-level or Doppler-radar data for altitudes up to approximately $12-16 \mathrm{~km}$. The CFADs either do not illustrate this characteristic or do not illustrate it as strongly as the CFADs in Black et al. (1996). For example, the $0.0625 \%-8 \%$ frequency contours for positive vertical velocity in Joaquin broaden with height to varying degrees (Fig. 11b), but not as strongly as observed in Black et al. (1996).

The CFADs between our study and Black et al. (1996) may differ because: 1 ) vertical velocity errors are largest aloft (see the appendix);2) sonde fall stability is likely a larger issue aloft; 3 ) there are three TCs in this study and seven TCs in Black et al. (1996); 4) the use of a differential pressure fall speed rather than the GPS fall speed produces weaker vertical velocities aloft (see supplemental material); 5) TC intensity, rate of intensity change, and time relative to peak intensity or rapid intensification can cause differences in CFADs (McFarquhar et al. 2012); 6) CFAD profiles can vary from storm-to-storm (Nguyen et al. 2017); 7) lack of radar data aloft and the use of a minimum reflectivity threshold drastically changes TC CFADs in the upper levels (McFarquhar et al. 2012; Nguyen et al. 2017); and 8 ) if the true geometric center of an updraft or downdraft is not sampled, then vertical velocity may be underestimated for the updraft or downdraft (Jorgensen et al. 1985). The TCI XDD CFADs more resemble the rainband and stratiform CFADs from Black et al. (1996) than the eyewall CFAD (Fig. 11). The CFADs do resemble the CFAD from simulations of Dennis (2005) near rapid intensification, but without a minimum reflectivity threshold (McFarquhar et al. 2012). Further, the similarities between the mean and median values (Table 2), profiles (Figs. 4-8), and the results in Black et al. (1996) provide support and increase confidence in the quality of the XDD-derived TCI vertical velocity dataset.

The azimuthal vertical velocity distributions (Fig. 10) do not show robust patterns and do not agree well with the canonical wavenumber-1 convective asymmetry within the core (e.g., Black et al. 2002; Corbosiero and Molinari 2002, 2003; Stern and Aberson 2006; Guimond et al. 2010; Reasor et al. 2013; DeHart et al. 2014), which could be due to the relatively small sample size. Further, it is possible that the convection was organized by vortex tilt rather than the 850-200-hPa shear (e.g., Stevenson et al. 2014). It is important to note that the $850-200-\mathrm{hPa}$ shear direction is a simple vector difference between two levels and assumes that the shear changes uniformly between the levels, whereas the tilt structure is a function of altitude through multiple layers and potentially exhibits more variability in space and time (e.g., Creasey and Elsberry 2017). It is also plausable that the shear strength or direction changes nonlinearly between the 850- and 200-hPa levels, which could account for these differences.

This discrepancy and lack of data, especially at outer radii, also suggests that more observations with an even distribution of samples in each shear-relative quadrant are likely required to analyze sonde-derived convective asymmetries in individual TCs using CFAzDs. Bootstrap analysis provided as supplemental material, however, suggests that Marty had the strongest median XDD-derived vertical velocities in the DL quadrant within the core, but the lack of data in each shearrelative quadrant make the finding unrobust. It is also important to remember that the CFAzDs are used to look at the azimuths with the highest frequency of 

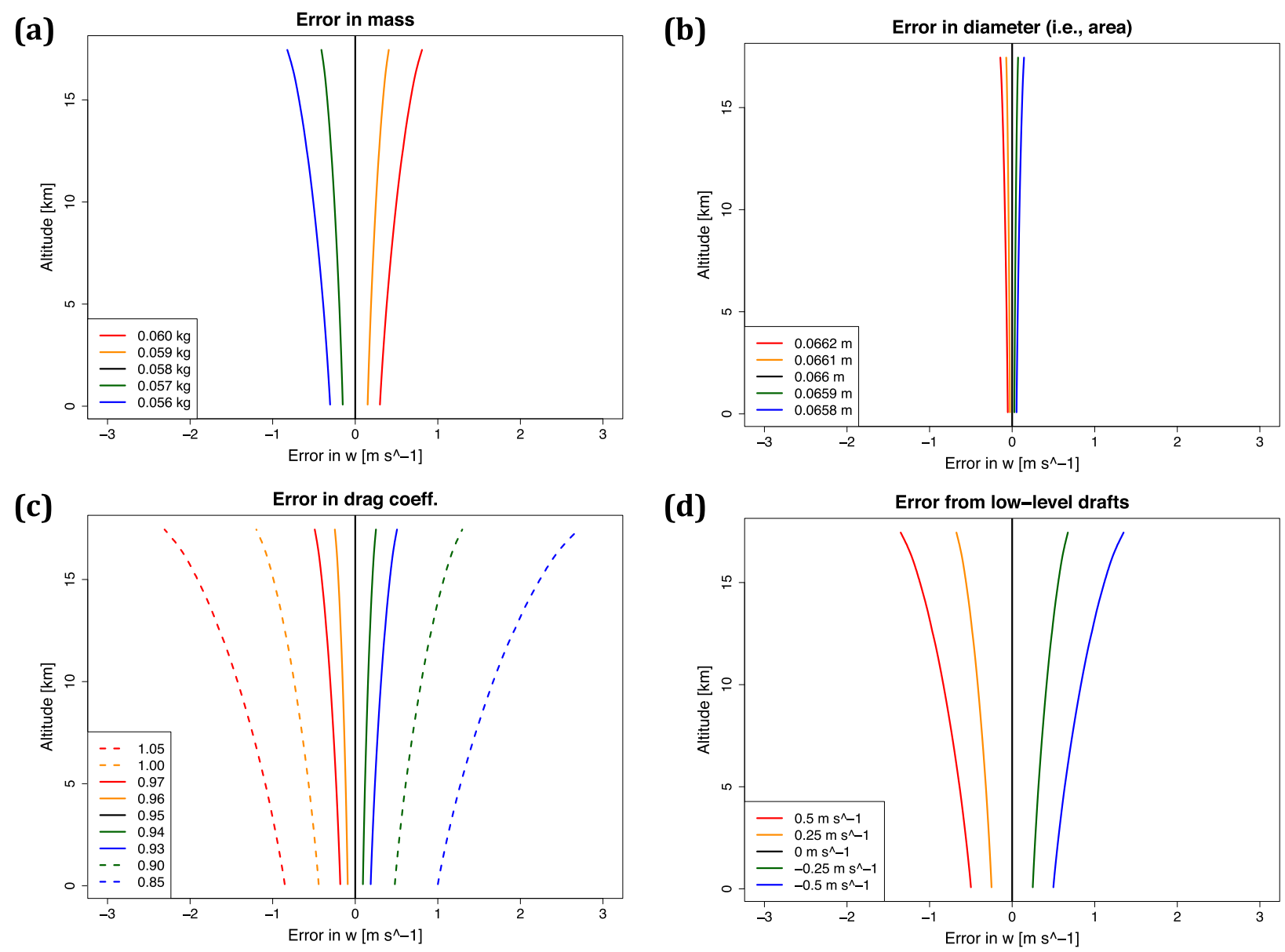

FIG. A1. Errors in vertical velocity for variations of (a) $m_{s}$, (b) diameter or $A$, (c) $C_{d}$, and (d) $w_{L}$.

vertical velocity, which can lead to discrepancies. For example, it is possible that a quadrant could have a relatively higher frequency of vertical velocities at an appreciable strength, but the mean or median strength within the quadrant may be considerably weaker.

To better understand sonde-derived vertical velocities, the errors associated with the calculation of vertical velocity need to be addressed. If GPS fall speeds are used in the calculation of vertical velocity, strict screening of the data must be conducted to remove large, unrealistic errors in the fall speed like in Fig. 1. If a maximum difference of $1 \mathrm{~m} \mathrm{~s}^{-1}$ between the GPS fall speed and the hydrostatic differential pressure fall speed is allowed, then 40168 data points from the subset TCI soundings used in this study would need to be removed or quality controlled. Stern et al. (2016) note, however, that using the differential pressure fall speed alone may introduce errors when examining extreme nonhydrostatic updrafts. This serves as justification for the improvement of the measurement of sonde fall speed and the decrease in sonde fall speed errors. As shown in the Appendix, the sonde-derived vertical velocity errors from the XDDs are approximately $\pm 1-2 \mathrm{~ms}^{-1}$. Optimistically, sonde-derived vertical velocity errors an order of magnitude smaller would improve the confidence of the vertical velocities between $\pm 2 \mathrm{~m} \mathrm{~s}^{-1}$, which accounts for a large portion of the vertical velocity distributions in TCs [e.g., Black et al. (1996) and Figs. 9-11].

Acknowledgments. The authors thank Patrick Duran, Chip N. Helms, Sarah D. Ditchek, Stephanie N. Stevenson, and Joshua J. Alland for insight and discussion. The authors also would like to thank the Office of Naval Research (ONR) for funding this research through the High Density Drop-Sonde Measurements Grant (1141135-1-78783). We also sincerely thank three anonymous reviewers for their comments and suggestions on a previous version of the manuscript. This research was conducted while TCN was under the 2015 Atmospheric Sciences Research Center (ASRC) Graduate Student Fellowship. We would also like to thank all of the principal investigators and others 
associated with TCI, including Yankee Environmental Systems.

\section{APPENDIX}

\section{Error Analysis of Vertical Velocity Methodology}

This section addresses potential errors associated with the vertical velocity calculation used in this study. The three major sources for error are as follows: 1) determination of $V_{o}$ and $\left.\rho_{o}, 2\right)$ sonde-to-sonde variations in the sonde parameter, and 3 ) the presence of weak lowlevel updrafts or downdrafts $\left(w_{L}\right)$ affecting the last data point fall speed of sondes outside of convective regions. In this study, a median sonde parameter is assumed to be representative for all sondes. It is plausible that the sonde parameter for any individual sonde differs from the median. Sonde-to-sonde variations in the sonde parameter include variations in sonde mass $\left(m_{s}\right)$, differences in drag area $(A)$, and variations in drag coefficient $\left(C_{d}\right)$. It is assumed here that changes in sonde mass during descent are possible through icing. It is currently unknown, however, to what degree icing occurs on the XDDs. Other dropsonde studies have also assumed that $C_{d}$, and therefore $A$, is constant, regardless of the angle of incidence ( $\mathrm{Li}$ and Miller 2014). While this is likely to be true, added mass from icing or deformation of the sonde body may lead to small changes in $A, m$, or $C_{d}$. It is also possible that the last data point fall speeds were skewed to higher or lower values due to the presence of low-level updrafts or downdrafts.

Plots of potential errors in the vertical velocity calculations are provided in Fig. A1 by varying $m_{s}, A, C_{d}$, and $V$ in Eqs. (1) and (2). Here, it is assumed that the drag force in Eq. (1) is equal to the gravitational force $\left(g m_{s}\right)$ and that the drag coefficient based upon the median sonde parameter is 0.95 . This assumes that the mass is $58 \mathrm{~g}$ and $A$ is calculated from the diameter of $0.066 \mathrm{~m}$ provided by Black et al. (2017). Other methods of obtaining $V_{o}$ and $\rho_{o}$ are provided as supplemental material.

For each plot in Fig. A1, errors are largest aloft where density is the smallest due to a larger ratio of $\rho_{o} / \rho$, which gives a larger, erroneous $w$. A $\pm 1 \mathrm{~g}$ change in mass of a sonde due to icing or manufacturing differences leads to errors of approximately $\pm 1 \mathrm{~m} \mathrm{~s}^{-1}$ aloft (Fig. A1a). As it is unlikely that a sonde's area will change drastically, the diameter is only allowed to vary by $0.0002 \mathrm{~m}$, leading to errors in $w$ between $\pm 0.14 \mathrm{~m} \mathrm{~s}^{-1}$ aloft (Fig. A1b). Errors due to underestimates or overestimates of the drag coefficient are shown in Fig. A1c and can vary between $\pm 2 \mathrm{~m} \mathrm{~s}^{-1}$ aloft if the drag coefficient is allowed to vary by 0.1 . An error in the last data point median fall speed of $\pm 0.5 \mathrm{~m} \mathrm{~s}^{-1}$ leads to errors of $\pm 1.36 \mathrm{~m} \mathrm{~s}^{-1}$ (Fig. A1d).
Based upon the standard deviation of the sonde parameter $\left(0.21 \mathrm{~kg}^{1 / 2} \mathrm{~m}^{3 / 2}\right)$, sonde-to-sonde differences within the standard deviation would cause errors of $\pm 0.8 \mathrm{~m} \mathrm{~s}^{-1}$ in the low levels and $\pm 2 \mathrm{~m} \mathrm{~s}^{-1}$ aloft.

\section{REFERENCES}

Aberson, S. D., M. T. Montgomery, M. Bell, and M. Black, 2006: Hurricane Isabel (2003): New insights into the physics of intense storms. Part II: Extreme localized wind. Bull. Amer. Meteor. Soc., 87, 1349-1354, https://doi.org/10.1175/BAMS-87-10-1349.

Bell, M. M., et al., 2016: ONR tropical cyclone intensity 2015 NASA WB-57 HDSS dropsonde data, version 1.0. UCAR/NCAREarth Observing Laboratory, accessed 1 Mar 2018, https:// doi.org/10.5065/D6KW5D8M.

Berg, R., 2016a: National Hurricane Center Tropical Cyclone Report: Hurricane Joaquin (28 September-7 October 2015). NHC Rep. AL112015, 36 pp., https://www.nhc.noaa.gov/data/ tcr/AL112015_Joaquin.pdf.

_ 2016b: National Hurricane Center Tropical Cyclone Report: Hurricane Marty (26-30 September 2015). NHC Rep. EP172015, 17 pp., https://www.nhc.noaa.gov/data/tcr/ EP172015_Marty.pdf.

Black, M. L., R. W. Burpee, and F. Marks Jr., 1996: Vertical motion characteristics of tropical cyclones determined with airborne Doppler radial velocities. J. Atmos. Sci., 53, 1887-1909, https:// doi.org/10.1175/1520-0469(1996)053<1887:VMCOTC > 2.0.CO;2.

— J. F. Gamache, F. D. Marks Jr., C. E. Samsury, and H. E. Willoughby, 2002: Eastern Pacific Hurricanes Jimena of 1991 and Olivia of 1994: The effect of vertical shear on structure and intensity. Mon. Wea. Rev., 130, 2291-2312, https://doi.org/ 10.1175/1520-0493(2002)130<2291:EPHJOA > 2.0.CO;2.

Black, P., L. Harrison, M. Beaubien, R. Bluth, R. Woods, A. Penny, R. Smith, and J. Doyle, 2017: High Definition Sounding System (HDSS) for atmospheric profiling. J. Atmos. Oceanic Technol., 34, 777-796, https://doi.org/10.1175/ JTECH-D-14-00210.1.

Black, R. A., H. B. Bluestein, and M. L. Black, 1994: Unusually strong vertical motions in a Caribbean hurricane. Mon. Wea. Rev., 122, 2722-2739, https://doi.org/10.1175/1520-0493(1994) 122<2722:USVMIA > 2.0.CO;2.

Bryan, G. H., and R. Rotunno, 2009: The influence of near-surface, high-entropy air in hurricane eyes on maximum hurricane intensity. J. Atmos. Sci., 66, 148-158, https://doi.org/10.1175/ 2008JAS2707.1.

Cecil, D., S. Biswas, W. Jones, and F. Alquaied, 2016: Hurricane imaging radiometer (HIRAD) data, version 2.1. UCAR/NCAREarth Observing Laboratory, accessed 26 July 2017, https:// doi.org/10.5065/D6CF9NGC.

Corbosiero, K. L., and J. Molinari, 2002: The effects of vertical wind shear on the distribution of convection in tropical cyclones. Mon. Wea. Rev., 130, 2110-2123, https://doi.org/ 10.1175/1520-0493(2002)130<2110:TEOVWS > 2.0.CO;2.

- , and - 2003: The relationship between storm motion, vertical wind shear, and convective asymmetries in tropical cyclones. J. Atmos. Sci., 60, 366-376, https://doi.org/10.1175/ 1520-0469(2003)060<0366:TRBSMV>2.0.CO;2.

,,- A. R. Aiyyer, and M. L. Black, 2006: The structure and evolution of Hurricane Elena (1985). Part II: Convective asymmetries and evidence for vortex Rossby waves. Mon. Wea. Rev., 134, 3073-3091, https://doi.org/10.1175/MWR3250.1. 
Creasey, R. L., and R. L. Elsberry, 2017: Tropical cyclone center positions from sequences of HDSS sondes deployed along high-altitude overpasses. Wea. Forecasting, 32, 317-325, https://doi.org/10.1175/WAF-D-16-0096.1.

DeHart, J. C., R. A. Houze Jr., and R. F. Rogers, 2014: Quadrant distribution of tropical cyclone inner-core kinematics in relation to environmental shear. J. Atmos. Sci., 71, 2713-2732, https://doi.org/10.1175/JAS-D-13-0298.1.

DeMaria, M., and J. Kaplan, 1994: A Statistical Hurricane Intensity Prediction Scheme (SHIPS) for the Atlantic basin. Wea. Forecasting, 9, 209-220, https://doi.org/10.1175/1520-0434(1994) 009<0209:ASHIPS >2.0.CO;2.

—, R. T. DeMaria, J. A. Knaff, and D. Molenar, 2012: Tropical cyclone lightning and rapid intensity change. Mon. Wea. Rev., 140, 1828-1842, https://doi.org/10.1175/MWR-D-11-00236.1.

Dolling, K., and G. M. Barnes, 2012: The creation of a high equivalent potential temperature reservoir in Tropical Storm Humberto (2001) and its possible role in storm deepening. Mon. Wea. Rev., 140, 492-505, https://doi.org/10.1175/MWRD-11-00068.1.

Doyle, J. D., and Coauthors, 2017: A view of tropical cyclones from above: The Tropical Cyclone Intensity (TCI) experiment. Bull. Amer. Meteor. Soc., 98, 2113-2134, https://doi.org/ 10.1175/BAMS-D-16-0055.1.

Duran, P., and J. Molinari, 2018: Dramatic inner-core tropopause variability during the rapid intensification of Hurricane Patricia (2015). Mon. Wea. Rev., 146, 119-134, https://doi.org/ 10.1175/MWR-D-17-0218.1.

Eastin, M. D., W. M. Gray, and P. G. Black, 2005a: Buoyancy of convective vertical motions in the inner core of intense hurricanes. Part I: General statistics. Mon. Wea. Rev., 133, 188-208, https://doi.org/10.1175/MWR-2848.1.

,-- , and -2005 b: Buoyancy of convective vertical motions in the inner core of intense hurricanes. Part II: Case studies. Mon. Wea. Rev., 133, 209-227, https://doi.org/10.1175/ MWR-2849.1.

Franklin, J. L., S. J. Ford, S. E. Feuer, and F. Marks Jr., 1993: The kinematic structure of Hurricane Gloria (1985) determined from nested analyses of dropwindsonde and Doppler radar data. Mon. Wea. Rev., 121, 2433-2451, https://doi.org/10.1175/ 1520-0493(1993)121<2433:TKSOHG > 2.0.CO;2.

Guimond, S. R., G. M. Heymsfield, and F. J. Turk, 2010: Multiscale observations of Hurricane Dennis (2005): The effects of hot towers on rapid intensification. J. Atmos. Sci., 67, 633-654, https://doi.org/10.1175/2009JAS3119.1.

Hazelton, A., R. Rogers, and R. Hart, 2017: Analyzing simulated convective bursts in two Atlantic hurricanes. Part I: Burst formation and development. Mon. Wea. Rev., 145, 3073-3094, https://doi.org/10.1175/MWR-D-16-0267.1.

Heymsfield, G. M., L. Tian, A. J. Heymsfield, L. Li, and S. Guimond, 2010: Characteristics of deep tropical and subtropical convection from nadir-viewing high-altitude airborne Doppler radar. J. Atmos. Sci., 67, 285-308, https://doi.org/ 10.1175/2009JAS3132.1.

Hock, T. F., and J. L. Franklin, 1999: The NCAR GPS dropwindsonde. Bull. Amer. Meteor. Soc., 80, 407-420, https://doi.org/ 10.1175/1520-0477(1999)080<0407:TNGD>2.0.CO;2.

Jiang, H., 2012: The relationship between tropical cyclone intensity change and the strength of inner-core convection. Mon. Wea. Rev., 140, 1164-1176, https://doi.org/10.1175/MWR-D11-00134.1.

— , and E. M. Ramirez, 2013: Necessary conditions for tropical cyclone rapid intensification as derived from 11 years of
TRMM data. J. Climate, 26, 6459-6470, https://doi.org/ 10.1175/JCLI-D-12-00432.1.

— , and C. Tao, 2014: Contribution of tropical cyclones to global very deep convection. J. Climate, 27, 4313-4336, https:// doi.org/10.1175/JCLI-D-13-00085.1.

Jorgensen, D. P., E. J. Zipser, and M. A. LeMone, 1985: Vertical motions in intense hurricanes. J. Atmos. Sci., 42, 839-856, https://doi.org/10.1175/1520-0469(1985)042<0839:VMIIH> 2.0.CO;2.

Kaplan, J., and M. DeMaria, 2003: Large-scale characteristics of rapidly intensifying tropical cyclones in the North Atlantic basin. Wea. Forecasting, 18, 1093-1108, https://doi.org/10.1175/ 1520-0434(2003)018<1093:LCORIT>2.0.CO;2.

Kimberlain, T. B., E. S. Blake, and J. P. Cangialosi, 2016: National Hurricane Center Tropical Cyclone Report: Hurricane Patricia (20-24 October 2015). NHC Rep. EP202015, 32 pp., https:// www.nhc.noaa.gov/data/tcr/EP202015_Patricia.pdf.

Li, S., and C. Miller, 2014: A study on the motion characteristics and their impact on the wind measurement post-processing of the GPS dropwindsonde. Part I: Effects of the wind-finding equations. Theor. Appl. Climatol., 117, 221-231, https:// doi.org/10.1007/s00704-013-0962-5.

Marks, F. D., P. G. Black, M. T. Montgomery, and R. W. Burpee, 2008: Structure of the eye and eyewall of Hurricane Hugo (1989). Mon. Wea. Rev., 136, 1237-1259, https://doi.org/ 10.1175/2007MWR2073.1.

McFarquhar, G. M., B. F. Jewett, M. S. Gilmore, S. W. Nesbitt, and T. Hsieh, 2012: Vertical velocity and microphysical distributions related to rapid intensification in a simulation of Hurricane Dennis (2005). J. Atmos. Sci., 69, 3515-3534, https:// doi.org/10.1175/JAS-D-12-016.1.

Montgomery, M. T., M. M. Bell, S. D. Aberson, and M. L. Black, 2006: Hurricane Isabel (2003): New insights into the physics of intense storms. Part I: Mean vortex structure and maximum intensity estimates. Bull. Amer. Meteor. Soc., 87, 1335-1347, https://doi.org/10.1175/BAMS-87-10-1335.

Moon, Y., and D. S. Nolan, 2015: Spiral rainbands in a numerical simulation of Hurricane Bill (2009). Part II: Propagation of inner rainbands. J. Atmos. Sci., 72, 191-215, https://doi.org/ 10.1175/JAS-D-14-0056.1.

Nguyen, L. T., R. F. Rogers, and P. D. Reasor, 2017: Thermodynamic and kinematic influences on precipitation symmetry in sheared tropical cyclones: Bertha and Cristobal (2014). Mon. Wea. Rev., 145, 4423-4446, https://doi.org/10.1175/MWR-D17-0073.1.

Persing, J., and M. T. Montgomery, 2003: Hurricane superintensity. J. Atmos. Sci., 60, 2349-2371, https://doi.org/10.1175/15200469(2003)060<2349:HS > 2.0.CO;2.

Reasor, P. D., R. Rogers, and S. Lorsolo, 2013: Environmental flow impacts on tropical cyclone structure diagnosed from airborne Doppler radar composites. Mon. Wea. Rev., 141, 2949-2969, https://doi.org/10.1175/MWR-D-12-00334.1.

Rogers, R., P. Reasor, and S. Lorsolo, 2013: Airborne Doppler observations of the inner-core structural differences between intensifying and steady-state tropical cyclones. Mon. Wea. Rev., 141, 2970-2991, https://doi.org/10.1175/MWR-D12-00357.1.

, J. A. Zhang, J. Zawislak, H. Jiang, G. R. Alvey III, E. J. Zipser, and S. N. Stevenson, 2016: Observations of the structure and evolution of Hurricane Edouard (2014) during intensity change. Part II: Kinematic structure and the distribution of deep convection. Mon. Wea. Rev., 144, 3355-3376, https://doi.org/ 10.1175/MWR-D-16-0017.1. 
Shapiro, L. J., and H. E. Willoughby, 1982: The response of balanced hurricanes to local sources of heat and momentum. J. Atmos. Sci., 39, 378-394, https://doi.org/10.1175/1520-0469(1982) 039<0378:TROBHT $>2.0$. CO;2.

Steranka, J., E. B. Rodgers, and R. C. Gentry, 1986: The relationship between satellite measured convective bursts and tropical cyclone intensification. Mon. Wea. Rev., 114, 1539-1546, https://doi.org/10.1175/1520-0493(1986)114<1539:TRBSMC> 2.0.CO;2.

Stern, D. P., and S. D. Aberson, 2006: Extreme vertical winds measured by dropwindsondes in hurricanes. 27th Conf. on Hurricanes and Tropical Meteorology, Monterey, CA, Amer. Meteor. Soc., 16B.8, https://ams.confex.com/ams/pdfpapers/ 108766.pdf.

— J. L. Vigh, and D. S. Nolan, 2015: Revisiting the relationship between eyewall contraction and intensification. J. Atmos. Sci., 72, 1283-1306, https://doi.org/10.1175/JAS-D-14-0261.1.

, G. H. Bryan, and S. D. Aberson, 2016: Extreme low-level updrafts and wind speeds measured by dropsondes in tropical cyclones. Mon. Wea. Rev., 144, 2177-2204, https://doi.org/ 10.1175/MWR-D-15-0313.1.
Stevenson, S. N., K. L. Corbosiero, and J. Molinari, 2014: The convective evolution and rapid intensification of Hurricane Earl (2010). Mon. Wea. Rev., 142, 4364-4380, https://doi.org/ 10.1175/MWR-D-14-00078.1.

Vigh, J. L., and W. H. Schubert, 2009: Rapid development of the tropical cyclone warm core. J. Atmos. Sci., 66, 3335-3350, https://doi.org/10.1175/2009JAS3092.1.

Wang, J., and Coauthors, 2015: A long-term, high-quality, highvertical-resolution GPS dropsonde dataset for hurricane and other studies. Bull. Amer. Meteor. Soc., 96, 961-973, https:// doi.org/10.1175/BAMS-D-13-00203.1.

Willoughby, H. E., and M. B. Chemlow, 1982: Objective determination of hurricane tracks from aircraft observations. Mon. Wea Rev., 110, 1298-1305, https://doi.org/10.1175/1520-0493(1982) $110<1298$ :ODOHTF $>2.0 . \mathrm{CO} ; 2$.

Zipser, E. J., 2003: Some views on "hot towers" after 50 years of tropical field programs and two years of TRMM data. Cloud Systems, Hurricanes, and the Tropical Rainfall Measuring Mission (TRMM), Meteor. Monogr., No. 51, 49-58, https:// doi.org/10.1175/0065-9401(2003)029<0049:CSVOHT $>$ 2.0.CO;2. 